\title{
Application of Scanning Tunneling Microscopy in Electrocatalysis and Electrochemistry
}

\author{
Haifeng Feng ${ }^{1,2} \cdot$ Xun $\mathrm{Xu}^{1,2} \cdot \mathrm{Yi} \mathrm{Du}^{1,2} \cdot$ Shi Xue Dou ${ }^{1,2}$
}

Received: 5 March 2020 / Revised: 12 May 2020 / Accepted: 3 July 2020 / Published online: 5 February 2021

(c) The Author(s) 2021

\begin{abstract}
Scanning tunneling microscopy (STM) has gained increasing attention in the field of electrocatalysis due to its ability to reveal electrocatalyst surface structures down to the atomic level in either ultra-high-vacuum (UHV) or harsh electrochemical conditions. The detailed knowledge of surface structures, surface electronic structures, surface active sites as well as the interaction between surface adsorbates and electrocatalysts is highly beneficial in the study of electrocatalytic mechanisms and for the rational design of electrocatalysts. Based on this, this review will discuss the application of STM in the characterization of electrocatalyst surfaces and the investigation of electrochemical interfaces between electrocatalyst surfaces and reactants. Based on different operating conditions, UHV-STM and STM in electrochemical environments (EC-STM) are discussed separately. This review will also present emerging techniques including high-speed EC-STM, scanning noise microscopy and tip-enhanced Raman spectroscopy.
\end{abstract}

keywords Electrochemist $\cdot$ Electrocatalyst $\cdot \mathrm{STM} \cdot$ EC-STM

\section{Introduction}

Low-cost, earth-abundant, highly efficient and stable electrocatalysts are crucial in the application of electrochemical techniques in modern industries, particularly for renewable energy conversion, fuel cell, energy storage and organic synthesis systems [1-6] in which, in general, they can be applied to either functionalize electrode surfaces or act directly as electrode surfaces to enhance reaction rates, efficiencies and selectivity. In recent decades, enormous improvements have been achieved in terms of electrocatalyst performances in a variety of applications such as water splitting, hydrogen fuel cells and $\mathrm{CO}_{2}$ reduction, mainly due to the detailed knowledge of electrocatalysts that has been achieved with the assistance of advanced characterization facilities and methods as well as theoretical calculations. As a result, the atomic and molecular-level understanding of

Shi Xue Dou

shi@uow.edu.au

1 Institute for Superconducting and Electronic Materials, Australian Institute for Innovative Materials, University of Wollongong, Wollongong, NSW 2500, Australia

2 BUAA-UOW Joint Research Centre, Beihang University, Haidian District, Beijing 100191, China electrocatalyst surfaces and corresponding electrochemical interfaces is indispensable for the rational optimization and design of electrocatalysts in which the knowledge of surface compositions, structures, defects and electronic structures as well as surface adsorbate configurations is key to identifying and increasing surface active sites and enhancing intrinsic activities [7, 8].

Scanning tunneling microscopy (STM) in ultra-high-vacuum (UHV) conditions has played a significant role in the field of surface sciences because it can allow for the study of surface structures at the atomic level to provide detailed information concerning the surface electronic structure of materials as well as the configuration, dynamics, dissociation and adsorption/desorption of surface adsorbates, all of which are vital in the application of materials such as noble metals, metal alloys and transition metal oxides in electrocatalytic or heterogeneous catalytic reactions $[9,10]$. In recent years, researchers have also combined electrochemical cells (EC cell) with UHV-STM through the introduction of transfer systems to effectively avoid contamination and oxidation during sample exchange [11-14], thus allowing for the electrochemical measurement of clean and welldefined electrocatalyst surfaces without exposure to air and promoting the in-depth correlation between surface-related properties and electrocatalytic performances. And because 
STM can also be operated under atmospheric pressures and aqueous environments to study material surfaces at the atomic resolution in addition to UHV conditions, STM can also be applied in the in situ investigation of electrochemical reactions through the direct identification and monitoring of active sites during electrocatalytic reactions with the STM tip acting as a working electrode, which is known as electrochemical STM (EC-STM) [15-18].

Based on these characteristics, this review will present the recent developments in the use of ex situ and in situ STM to study the catalytic mechanisms of electrocatalysis and identify the surface active sites of electrocatalysts. Information concerning the use of STM for heterogeneous catalysts that are not relevant to electrochemical applications is not included in this review; however, it can be found in other review articles [7, 19-21]. Specifically, this review will present state-of-the-art studies that use ex situ UHV-STM and UHV-STM/EC cell combined systems in the investigation of electrocatalyst surfaces with the aim of identifying surface active sites and revealing corresponding electrochemical properties, with studies on different electrocatalysts being classified based on composite type. In addition, recent developments involving the use of EC-STM in solution environments mainly on metal surfaces are discussed with corresponding electrochemical interfaces and electrode processes being emphasized. Furthermore, this review will introduce emerging STM techniques, including high-speed EC-STM, scanning noise microscopy and tip-enhanced Raman spectroscopy.

\section{UHV-STM and UHV-STM Combined with EC Cells}

\subsection{Noble Metal and Alloy-Based Electrocatalysts}

Noble metals as well as corresponding alloys and oxides are traditional electrocatalysts in many electrochemical applications due to excellent catalytic performances with examples including Pt-based electrocatalysts for hydrogen evolution reactions (HER), oxygen reduction reactions (ORR) and hydrogen oxidation reactions (HOR) as well as $\mathrm{Ir} / \mathrm{Ru}$ oxides for oxygen evolution reactions (OER). Here, surface and interface engineering approaches, including the control of surface structures and facets, alloying with other metals, construction of heterogeneous structures, etc., have been widely adopted not only to reduce noble metal loading, but also to enhance the intrinsic activity of surface active sites [22-27]. And in these attempts, both UHV-STM and EC-STM (Sect. 3) can play a vital role in the diagnosis of surface structures, morphologies and surface active sites as well as providing valuable assistance in the construction of structural models for theoretical simulations.
The alloying of noble metals is exemplified by the alloying of $\mathrm{Pt}$ with $3 d$ transition metals such as $\mathrm{Fe}, \mathrm{Co}, \mathrm{Ni}$ and $\mathrm{Ti}$ that can result in significant improvements in ORR activity as compared with pure Pt catalysts [28-31]. These enhanced electrocatalytic activities can usually be explained by the modified surface electronic property and activity of active sites and are known as the $d$-band center theory. Here, corresponding clean single-crystal surfaces prepared in UHV environments are suitable for the study of these modified surface electronic properties and their correlation with electrocatalytic activity.

For example, in the study of noble metal alloy $\mathrm{Pd}_{3} \mathrm{Fe}(111)$ obtained after annealing in UHV at $1200 \mathrm{~K}$ and $1000 \mathrm{Kin}$ which the samples were quickly transferred to an EC cell with the assistance of a small high-pressure antechamber/ load lock, Yang et al. [32] reported that the sample annealed at $1200 \mathrm{~K}$ exhibited the best ORR performance as compared with $\mathrm{Pd}(111)$ and $\mathrm{Pt}(111)$ based on electrochemical ORR testing and was able to attribute this performance to the highly active dispersed Fe adatoms based on STM results (Fig. 1a, b). With the same setup, Yang et al. [33, 34] also conducted the nanofaceting of $\operatorname{Re}(11 \overline{2} 1)$ as induced by carbon in UHV and used STM (Fig. 1c) to propose a surface

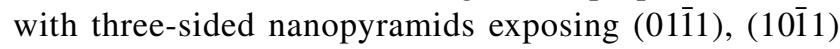
and (1120) facets (Fig. 1d). This surface was subsequently adopted as a template for monolayer Pt nanostructures to allow for higher activities toward HER than $\mathrm{Pt}(111)$ in acidic media. Furthermore, Wang et al. [34] used STM to study the nitrogen-induced nanofaceting of $\operatorname{Re}(11 \overline{2} 1)$ consisting of

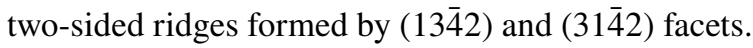

In a further study, Todoroki et al. [35] deposited Ni onto the surface of $\operatorname{Pt}(111)$ and obtained eight times higher ORR activities as compared with clean $\operatorname{Pt}(111)$, but reported that activities decreased steeply during potential cycling between 0.6 and $1.0 \mathrm{~V}$ to a two-time higher activity after 1000 potential cycles. Here, these researchers combined UHV-STM with molecular beam epitaxy (MBE) and an EC cell in a stainless steel glove box to avoid the exposure of their sample to air before and after cyclic voltammetry (CV) tests to allow for the examination of corresponding surface structures and the linking of surface structure to electrochemical activity. As a result, these researchers were able to propose based on the obtained STM topologies before and after 1000 potential cycles (Fig. 1g, h) that the underlying Ni-induced specific surface strain and the electronic state of the Ni/Pt(111) alloyed surface were the contributors to the remarkable ORR activity. With the same setup, the ORR activity of bimetallic surfaces prepared under UHV, including Pt/Au(hkl) [36], $\mathrm{Pt} / \mathrm{Ni} / \mathrm{Pt}(111)$ [37], $\mathrm{Pt} / \mathrm{Ni} / \mathrm{Pt}(110)$ [38], $\mathrm{Pt} / \mathrm{Pd}(111)$ [39] and $\mathrm{Pt} / \mathrm{Pt}_{25} \mathrm{Ni}_{75}$ (111) [40], has also been investigated.

Todoroki et al. [41] also examined the electrochemical $\mathrm{CO}_{2}$ reduction performance of epitaxially grown $\mathrm{Ni}$ and $\mathrm{Pt}$ on 

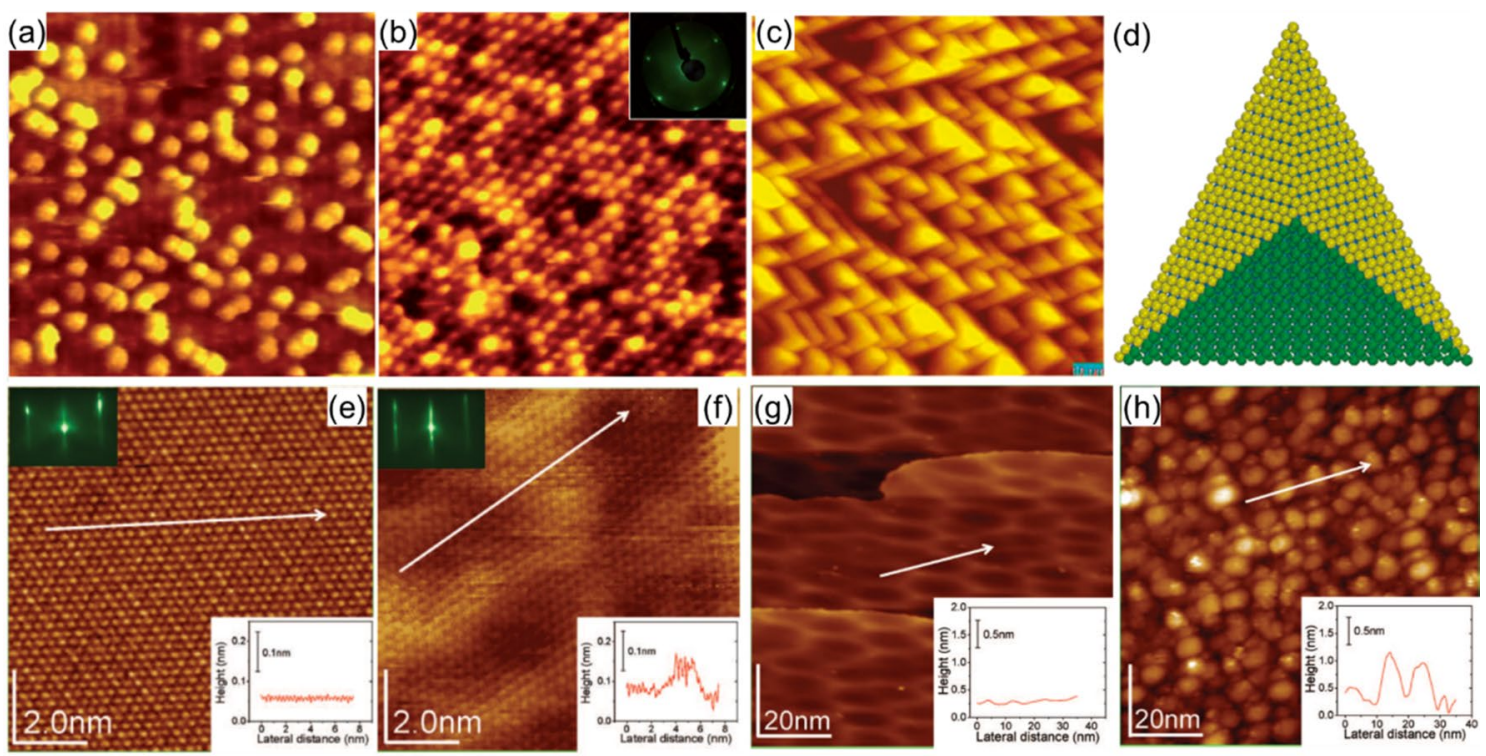

Fig. 1 a STM image of a $\mathrm{Pd}_{3} \mathrm{Fe}(111)$ surface obtained after annealing at $1200 \mathrm{~K}$ showing Pd adatoms on the surface. b STM image of a $\mathrm{Pd}_{3} \mathrm{Fe}(111)$ surface obtained after annealing at $1000 \mathrm{~K}$ showing a flat alloy surface with bright spots being identified as $\mathrm{Fe}$ atoms. Inset is the corresponding low-energy electron diffraction (LEED) pattern. Reprinted with permission from Ref. [32]. Copyright (C) 2011 WILEY-VCH Verlag GmbH\&Co. KGaA, Weinheim. c STM image of a nanofaceted $\mathrm{C} / \operatorname{Re}(1 \overline{2} 11)$ surface. d Hard spear model of a single pyramid for the nanofaceted $\mathrm{C} / \operatorname{Re}(11 \overline{2} 1)$ surface. Reprinted with per-

$\mathrm{Cu}(111)$ using STM and found that the growth of Pt monolayers on $\mathrm{Cu}(111)$ can increase total faradaic efficiencies to be comparable to that of $\mathrm{Pt}(111)$ and that the growth of $\mathrm{Ni}$ monolayers on $\mathrm{Cu}(111)$ can increase the selectivity for $\mathrm{CH}_{4}$ production above that of clean $\mathrm{Ni}(111)$, demonstrating that both the activity and selectivity of electrochemical $\mathrm{CO}_{2}$ reduction using $\mathrm{Cu}$-based alloys can be modified through surface alloying by affecting the formation of adsorbed $\mathrm{CO}$ intermediates.

In another study, Todoroki et al. [42] applied UHV-STM to assist in the study of low-index Au(hkl) surfaces using online electrochemical mass spectrometry in which $\mathrm{Au}(110)$ exhibited superior electrochemical $\mathrm{CO}_{2}$ reduction to $\mathrm{CO}$ as compared with $\mathrm{Au}(100)$ and (111) surfaces. Using the same experimental facilities, these researchers also demonstrated that with a 0.1 monolayer of $\mathrm{Co}$ on $\mathrm{Au}(110)$, the selectivity and partial current density of electrochemical $\mathrm{CO}_{2}$ reduction to $\mathrm{CO}$ can be enhanced as compared with clean $\mathrm{Au}(110)$, whereas with a 0.1 monolayer of $\mathrm{Sn}$ on $\mathrm{Au}(110)$, the selectivity of HER to $\mathrm{H}_{2}$ can be increased with the selectivity of $\mathrm{CO}_{2}$ reduction to $\mathrm{CO}$ decreased [43].

\subsection{Transition Metal Oxide-Based Electrocatalysts}

Earth-abundant transition metal oxides (TMOs) are appealing alternatives to noble metal (Ir and $\mathrm{Ru}$ )-based mission from Ref. [33]. Copyright (c) 2012 American Chemical Society. e Atomic-resolution STM image of a Pt(111) surface. f Atomicresolution STM image of a $\mathrm{Ni} / \mathrm{Pt}(111)$ surface. Upper left insets in (e, f) are corresponding RHEED patterns. $\mathbf{g}$ Large-scale STM image of an as-prepared $\mathrm{Ni} / \mathrm{Pt}(111)$ surface. $\mathbf{h}$ Large-scale STM image of a $\mathrm{Ni} / \mathrm{Pt}(111)$ surface after 1000 potential cycles. Lower right insets in $(\mathbf{e}-\mathbf{h})$ are corresponding line profiles along the arrows. Reprinted with permission from Ref. [35]. (C) 2013 The Electrochemical Society

electrocatalysts for electrochemical OER in alkaline media $[44,45]$. Great efforts have also been made in the development of TMOs for other electrocatalytic applications, especially as bifunctional electrocatalysts for HER/OER and OER/ORR reactions [46-50]. To increase the electrocatalytic activity of these TMOs, strategies such as the engineering of defects, the construction of mixed oxides and the introduction of noble metal nanostructures have been adopted in the attempt to increase active site numbers and enhance activities. And as compared with the surface of noble metals, the characterization of TMO surfaces using STM is more difficult due to lower conductivities and limited access to corresponding single crystals.

Over the years, the surface of TMOs as well the adsorption and reaction of corresponding adsorbates such as molecules of water, oxygen and $\mathrm{CO}$ on $\mathrm{TiO}_{2}$ has been intensively studied [51, 52]. Because the intrinsic conductivity of most TMOs is poor, however, corresponding defects, heterogeneous centers containing noble metals or the addition of conductive supports is indispensable in their application as electrocatalysts. Here, STM can be combined with ex situ electrochemical measurements for performance validation. For example, Feng et al. [53] combined STM with ex situ electrochemical measurements to study the reduced pure single crystal of rutile $\mathrm{TiO}_{2}(110)$ and found that corresponding 
electrocatalytic HER activities in alkaline media relied on $\mathrm{Ti}^{3+}$ ions to promote electron transfer and hydrogen desorption.

Instead of single-crystal TMOs, ultra-thin oxide islands or films are more accessible on metals produced through epitaxial growth and can be used as model catalysts in the study of catalytic mechanisms and interfacial (TMO/metal) effects in catalysis $[54,55]$. As a result, a variety of metal oxides and TMOs on metal surfaces has been successfully fabricated and studied using STM [56-63], and among these, cobalt oxides have received broad attention due to excellent OER performances [64-66]. For example, Fester et al. [67] were able to find through the in situ dosing of water molecules in an UHV chamber that exposed Co atoms on cobalt oxide nanoparticle edges rather than oxygen vacancies on basal planes acted as OER active sites to dissociate water and involved the hydroxylation of cobalt oxides. Here, atom-resolved STM snapshots of single-layer $\mathrm{CoO}$ islands
Fig. 2 a-c In situ STM snapshots and saturation level of hydroxylation. a, b Image sequences from atom-resolved STM video recorded at the initial stage of water exposure on single- (a) and double- (b) bilayer $\mathrm{CoO}$ nanoislands. Insets are corresponding high-magnification STM images. c STM image of a heavily hydroxylated single-bilayer island. $\mathbf{d}$ DFT-calculated hydroxylation structure of the $\mathrm{CoO}$ basal plane as a function of $\mathrm{H}$ chemical potential and pressure at room temperature. Reprinted with permission from Ref. [67]. Copyright (C) 2017, Springer Nature. e STM image of Co-O bilayer nanoislands on $\mathrm{Au}(111)$. f Structural model corresponding to $\mathrm{Co}-\mathrm{O}$ bilayer nanoislands. g STM image of a 0.3 monolayer cobalt oxide/Au(111) surface after HER. i Cathodic scan of the sample in (g) in the HER potential region as compared with clean $\mathrm{Au}(111)$. h STM image of a $\mathrm{Co}-\mathrm{O} /$ $\mathrm{Au}(111)$ surface after OER with corresponding CV curves in (j). Reprinted with permission from Ref. [68].๑ 2018 Wiley-VCH Verlag GmbH\&Co. KGaA, Weinheim
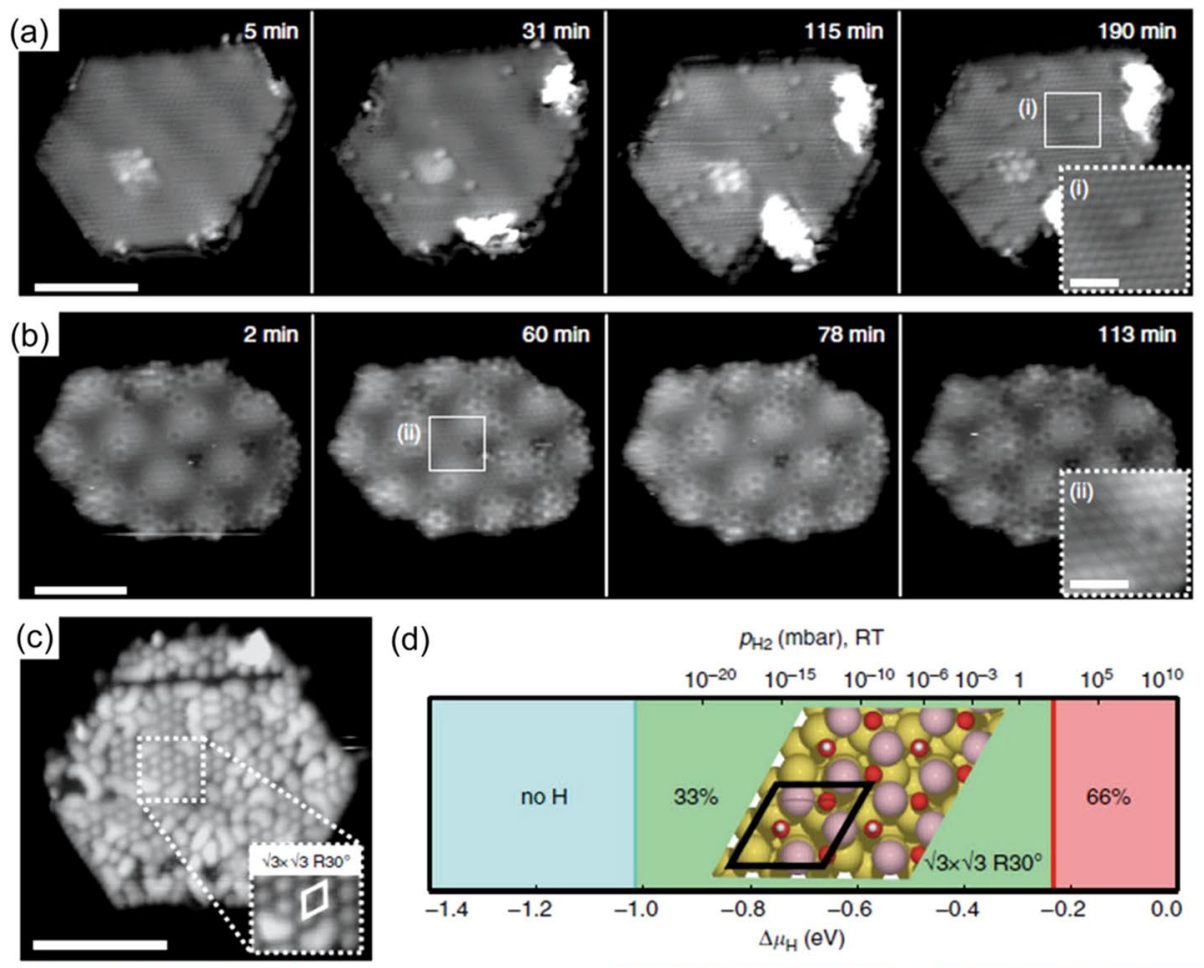

(d) $\quad p_{\mathrm{H}_{2}}$ (mbar), RT
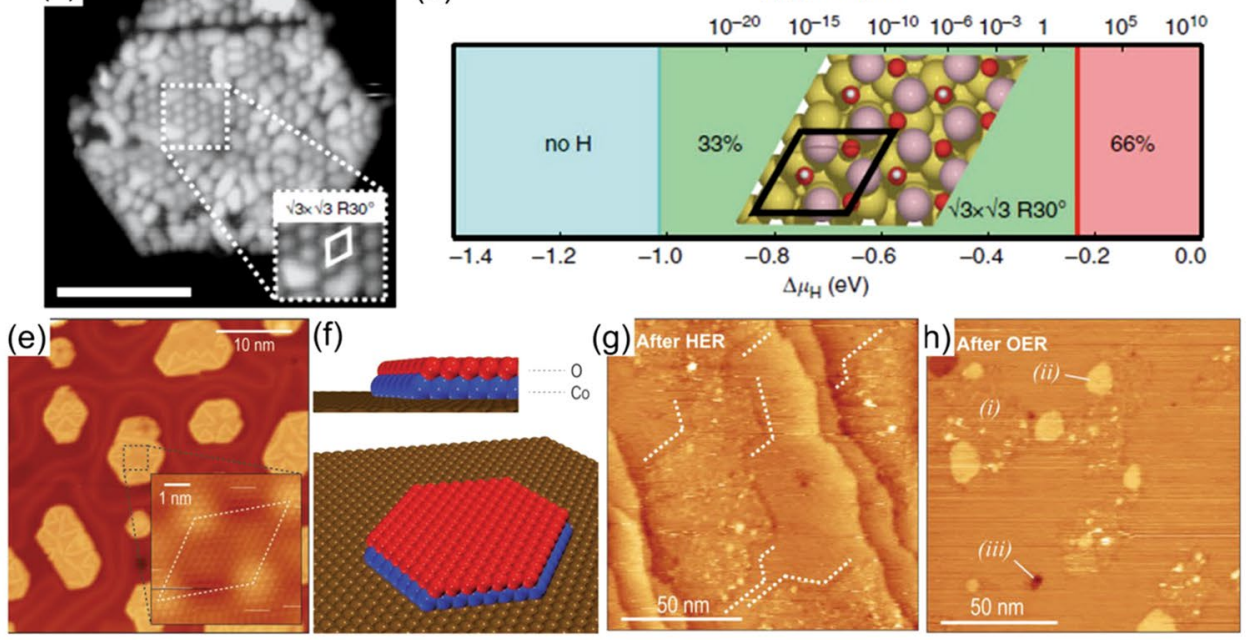

(i)

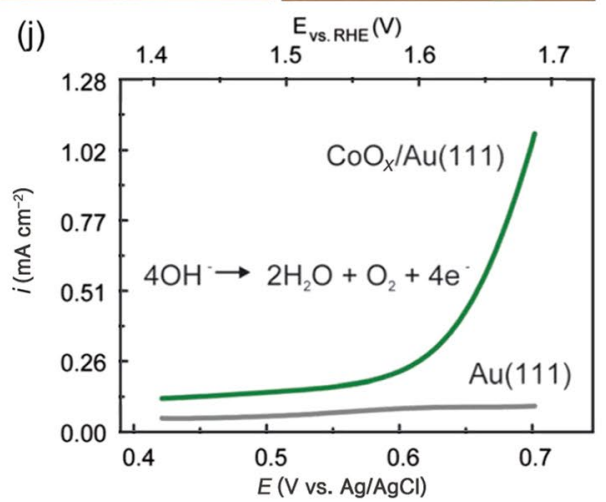


and bilayer $\mathrm{CoO}$ islands on $\mathrm{Au}(111)$ (Fig. 2a, b) revealed that new hydroxyl oxygen atoms with point-like features first formed at the edges and subsequently diffused to the basal plane during in situ water exposure in the UHV chamber and that at higher water dosages, an ordered $\sqrt{3} \times \sqrt{3}$ $\mathrm{R} 30^{\circ}$ structure of hydroxyls formed on the surface of $\mathrm{CoO}$ (Fig. 2c), which was also supported by density functional theory (DFT) calculations (Fig. 2d).

Fester et al. [68] further used these atomically defined $\mathrm{CoO}$ nanoislands on $\mathrm{Au}(111)$ (Fig. 2e, f) to study interfacial effects in electrocatalytic reactions through a CV measurement and STM combined system in which a preparation chamber was used as a transfer system to avoid the exposure of samples to air. As a result, these researchers were able to find that $\mathrm{Co}-\mathrm{O} / \mathrm{Au}(111)$ exhibited greatly enhanced HER and OER activities in alkaline media as compared with pure $\mathrm{Au}(111)$ (Fig. 2g, i). In addition, STM images of $\mathrm{Co}-\mathrm{O} / \mathrm{Au}(111)$ after HER CV tests (Fig. 2h) indicated the significant agglomeration of $\mathrm{Co}-\mathrm{O}$ islands due to reordering, whereas after OER CV tests, the morphology of Co-O islands showed only slight changes, confirming the OER activity enhancement of Au-supported cobalt oxide. These results also demonstrated that optimal enhancements occurred at below one monolayer of oxide due to the active stabilizing effect of $\mathrm{Au}(111)$, which will diminish if oxide films are too thick.

\section{3 $\operatorname{MoS}_{2}$-Based Electrocatalysts}

Nanoparticulate $\mathrm{MoS}_{2}$ electrocatalysts have also exhibited high activities in terms of electrochemical HER in acidic media that are competitive with state-of-the-art Pt-based electrocatalysts. Here, Hinnemann et al. [69] identified the active sites of nanoparticulate $\mathrm{MoS}_{2}$ electrocatalysts as the edge of $\mathrm{MoS}_{2}$ nanoparticles through the evaluation of calculated adsorbed $\mathrm{H}$ free energies and proposed a model electrocatalyst system composed of $\mathrm{MoS}_{2}$ nanoparticles and graphite supports that was successfully fabricated and characterized using UHV-STM (Fig. 3). This model was subsequently validated through numerous experimental results [70, 71], and in particular, Jaramilloa et al. [70] fabricated a series of $\mathrm{MoS}_{2}$ nanoparticles on $\mathrm{Au}(111)$ with different ratios of basal plane sites to edges sites and used UHV-STM for in-depth characterizations. These researchers also transferred the well-defined samples of $\mathrm{MoS}_{2}$ on $\mathrm{Au}(111)$ into EC cells without exposure to air for electrochemical characterization, thus allowing for the easy correlation of the lower overpotential of the sample obtained at $440{ }^{\circ} \mathrm{C}$ to the larger number of active sites due to smaller island sizes and more edge sites and demonstrating that the edge sites were the active sites of $\mathrm{MoS}_{2}$ in electrochemical HER.

Based on this fundamental understanding, great efforts have been made in corresponding material synthesis to increase the ratio of edge sites to basal sites for higher activities [72-74] in which molybdenum sulfide clusters including $\left[\mathrm{Mo}_{3} \mathrm{~S}_{4}\right]^{4+},\left[\mathrm{Mo}_{3} \mathrm{~S}_{13}\right]^{2-}$ and $\left[\mathrm{Mo}_{2} \mathrm{~S}_{12}\right]^{2-}$ with more $\mathrm{S}$ atoms arranged in a structural motif similar to the edges of $\mathrm{MoS}_{2}$ have demonstrated outstanding HER activities with lower overpotentials and excellent turnover frequencies (TOF) [75-77]. In terms of the use of STM, Kibsgaard et al. [76] successfully applied STM in the study of $\left[\mathrm{Mo}_{3} \mathrm{~S}_{13}\right]^{2-}$ to acquire the atomic-resolution structure of single clusters on a highly orientated pyrolytic graphite (HOPG) substrate and reported that STM can play a vital role in the identification of intrinsic structures, which can further be applied in the calculation of TOF by providing the number of active sites.

The surfaces of $\mathrm{MoS}_{2}$ and many other transition metal dichalcogenides (TMDs) have also been widely studied using UHV-STM due to interesting properties in terms of both catalysis and physics. And although most of them, prepared either in UHV through MBE or through the in situ cleavage of single crystals, have yet been directly studied using electrochemical measurements, existing knowledge involving surface defects [78-80], dopants [81], structural phases and phase boundaries [82, 83]
Fig. 3 Left: Polarization curve for HER on Pt, Daihope C support and $\mathrm{MoS}_{2}$ as cathodes. Right: STM image of $\mathrm{MoS}_{2}$ nanoparticles on graphite with enlargement in the inset. Reprinted with permission from Ref. [69]. Copyright (C 2005 American Chemical Society
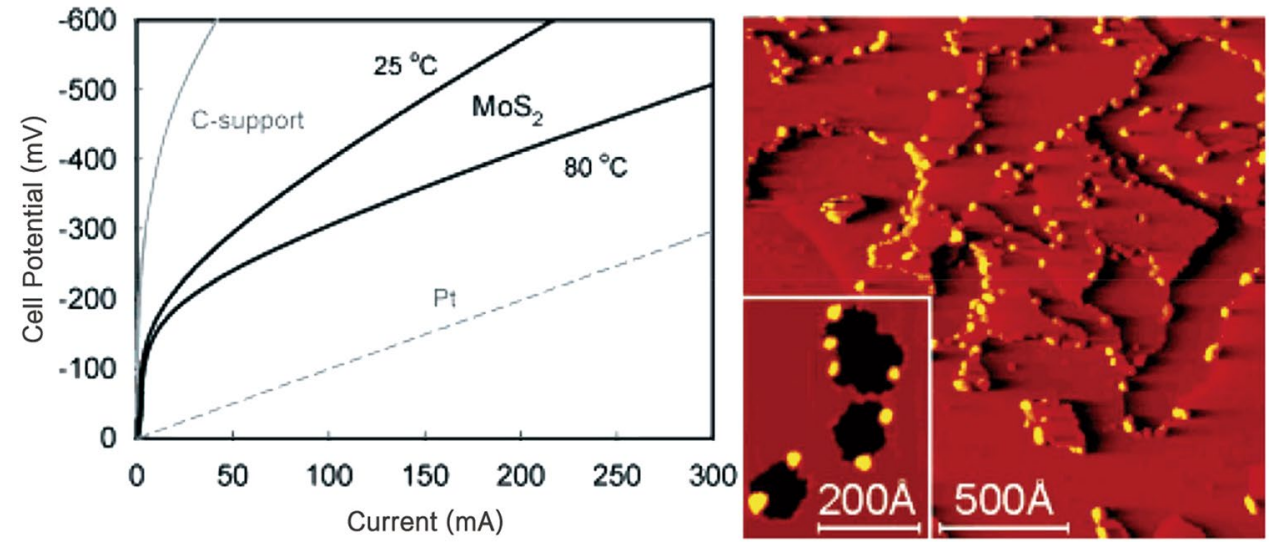
as well as hybridizations and heterostructures [84-86] is of importance in the revealing of corresponding surface active sites and the elucidation of electrocatalytic mechanisms.

\subsection{Metal-Supported Organic Molecule-Based Electrocatalysts}

In addition to solid crystal materials, many organic molecules are also promising candidates in numerous catalytic applications due to easy accessibility and chemical and thermal stability along with structural tunability at the molecular level [87-92]. As a result, metal-supported organic molecules including metallo-phthalocyanines (MPcs), metallo-porphyrins (MPps) and metal-organic coordination networks (MOCNs) have been widely studied as model electrocatalysts using UHV-STM to reveal structures as well as molecule-molecule and molecule-substrate interactions [93-101].

For example, Sedona et al. [99] were able to use STM to acquire the high-resolution image of $\mathrm{Fe}$ phthalocyanines (FePcs) on $\mathrm{Ag}(110)$ in which three different configurations were identified, with R1-LD and R2-LD in the submonolayer and $\mathrm{O}-\mathrm{HD}$ in the approximate single monolayer
(Fig. 4a-c). With these high-resolution images, these researchers were able to examine the corresponding activities of each structure toward oxygen reduction through the in situ dosing of oxygen in a UHV chamber and characterize the surfaces before and after oxygen dosing. Here, these researchers found that the $\mathrm{Fe}$-centered bright features on the mixed R1/R2-LD surface at a positive sample bias progressively disappeared during oxygen dosing, but recovered after annealing at $370 \mathrm{~K}$ for $60 \mathrm{~min}$ (Fig. $4 \mathrm{~d}-\mathrm{g}$ ), whereas the $\mathrm{O}-\mathrm{HD}$ FePc structure on $\mathrm{Ag}(110)$ showed almost no activity toward oxygen reduction (Fig. 4h, i), clearly demonstrating the different oxygen reduction activities of the different surface structures of FePcs.

In another study, Grumelli et al. [100] rationally prepared a two-dimensional (2D) MOCN on $\mathrm{Au}(111)$ for electrochemical ORR and used an UHV-STM and EC cell measurement combined system connected by a transfer system to study the resulting samples in which two molecular networks of benzene-1,3,5-tricarboxylic acid-Fe (TMA-Fe) and 5,50-bis(4pyridyl)(2,20-bipirimidine) (PBP-Fe) were observed (Fig. 5a-d). And as combined with electrochemical testing (Fig. $5 \mathrm{~g}, \mathrm{~h}$ ), these researchers were able to demonstrate that the metal centers of the samples determined the final product as well as the electrocatalytic mechanism in which the $\mathrm{Fe}$
Fig. 4 a-c STM images of monolayer FePc on $\operatorname{Ag}(110)$ : a R1-LD phase, b R2-LD phase and $\mathbf{c} \mathrm{O}-\mathrm{HD}$ phase with respective unit cells indicated by corresponding blue lines. d STM image of a R1/R2-LD $\mathrm{FePc} / \mathrm{Ag}(110)$. e STM image of a R1/R2-LD FePc/Ag(110) after dosing with $1700 \mathrm{~L}$ oxygen at room temperature. f STM image of the annealed surface $(370 \mathrm{~K}$, $60 \mathrm{~min}$ ) of an oxygen dosed R1/ R2-LD FePc/Ag(110). g Highresolution STM images of FePc molecules in the R2-LD phase: top (as deposited), middle (after oxygen dosage) and bottom (healed surface after annealing). h STM image of an O-HD $\mathrm{FePc} / \mathrm{Ag}(110)$. i STM image of an O-HD FePc/Ag(110) after dosing with $1700 \mathrm{~L}$ oxygen at room temperature. Reprinted with permission from Ref. [99]. Copyright () 2012, Springer Nature (a)

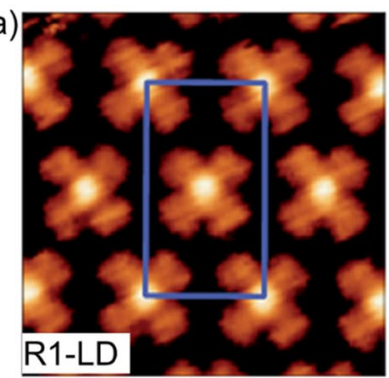

(d)

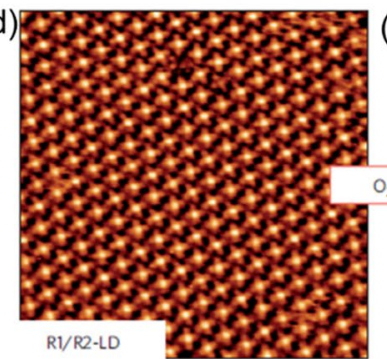

(g)

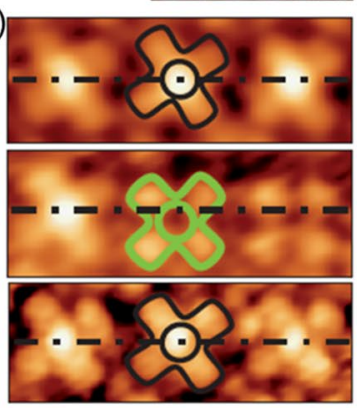

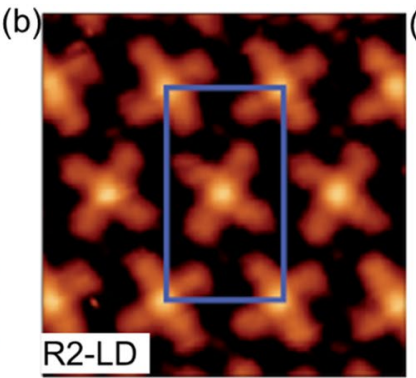

(e)
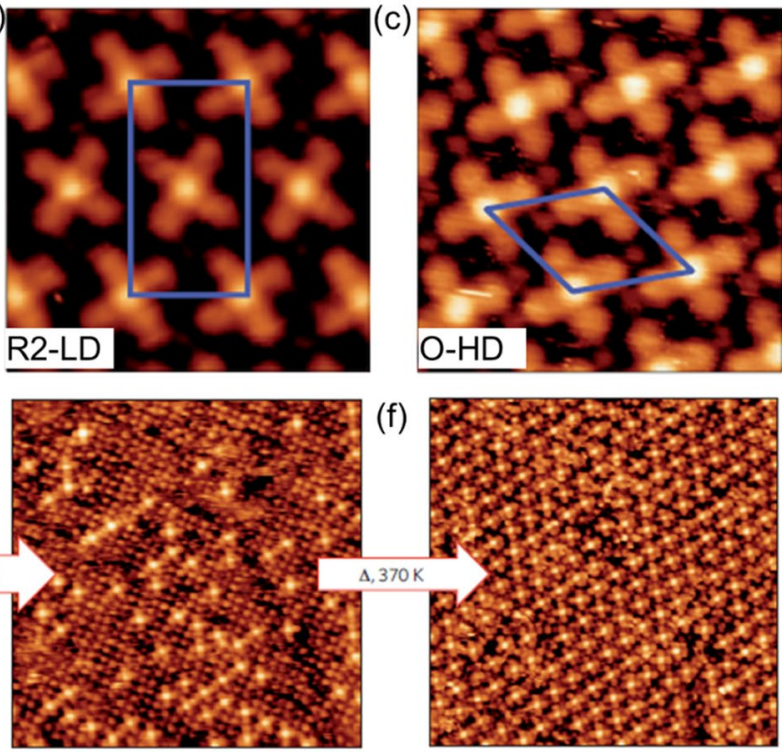

(f)

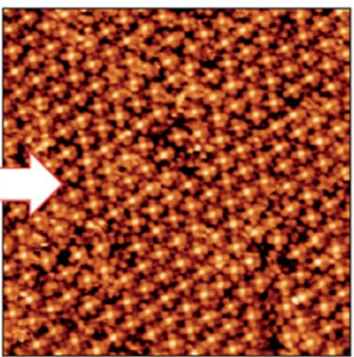

(h)

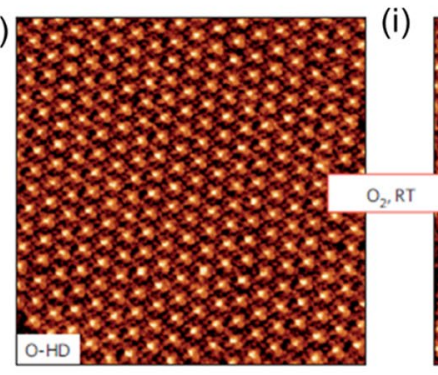

(i)

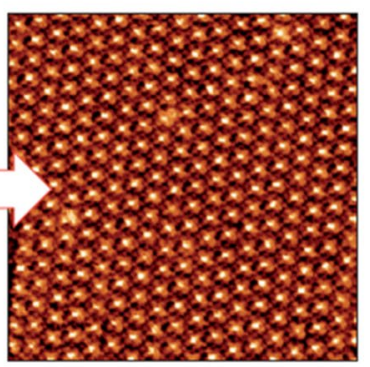



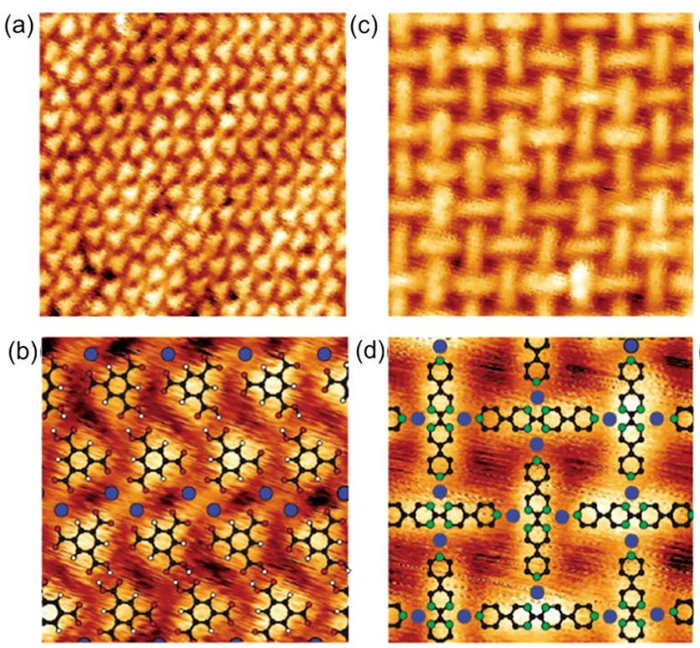

Fig. 5 a STM image of a TMA-Fe network on $\mathrm{Au}(111)$. b Highresolution STM image of a TMA-Fe network with the model superimposed. c STM image of a PBP-Fe network on $\mathrm{Au}(111)$. d High-resolution STM image of a PBP-Fe network with the model superimposed. e Large-scale STM image of a PBP-Fe network on $\mathrm{Au}(111)$ after EC tests. f Zoomed in STM image of (e). g EC ORR test in $0.1 \mathrm{M} \mathrm{NaOH}$ solution: bare $\mathrm{Au}(111)$ (gray solid line), TMA-Fe

centered TMA-Fe and PBP-Fe exhibited a $(2+2) \mathrm{e}^{-}$mechanism, whereas a TMA-Mn network can directly reduce $\mathrm{O}_{2}$ to $\mathrm{H}_{2} \mathrm{O}$ through a $4 \mathrm{e}^{-}$pathway. The nearly unchanged STM images of the sample surfaces before and after electrochemical testing also revealed the excellent reversibility and stability of these metal-organic networks (Fig. 5e, f). In a subsequent study, these researchers also studied heterobimetallic catalysts involving M1-TPyP-M2 (M1, M2 $=\mathrm{Fe}$ or $\mathrm{Co}$, $\mathrm{TPyP}=5,10,15,20$-tetrakis(4-pyridyl)porphyrin) and reported almost 2 orders of magnitude increases in OER activity as compared with homometallic catalysts [101].

\section{EC-STM}

EC-STM operates in electrolyte solutions and combines STM with EC cells. As a result, EC-STM can provide atomic- or molecular-level surface structures of electrocatalysts and chemical processes at the solid-liquid interface, thus allowing for the in situ monitoring of electrocatalyst surface structures and electrode processes including adsorption/desorption and dissociation of adsorbates under reaction conditions [16, 102]. Unlike STM operating under UHV conditions, the typical setup of EC-STM consists of two independent working electrodes (tip and sample), a reference electrode and a counter electrode, which allows for the simultaneous measuring of electrochemical currents (between sample and counter electrode) and tunneling currents (between tip and sample). Aside from tunneling
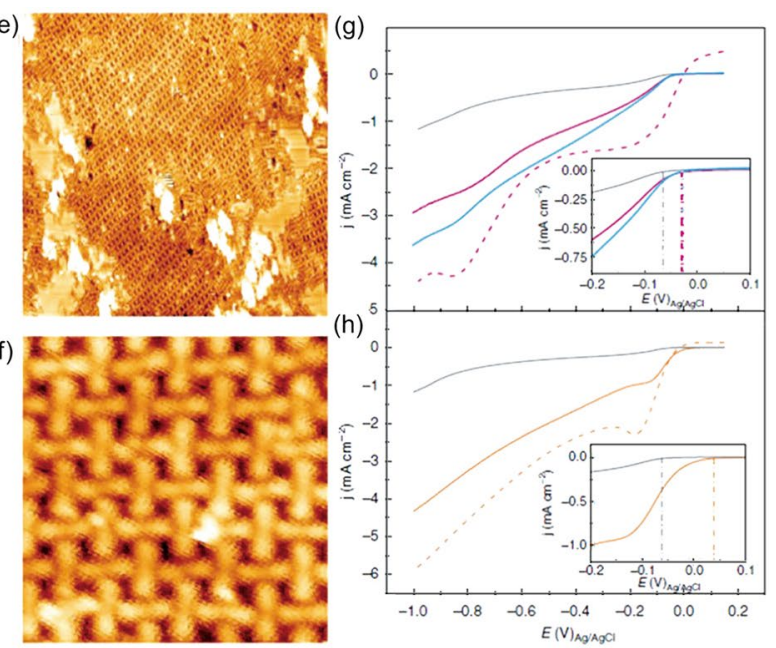

(pink solid line), PBP-Fe (turquoise solid line) and TMA-Fe after the addition of $10 \mathrm{mM} \mathrm{H}_{2} \mathrm{O}_{2}$ (pink dashed line). h Bare $\mathrm{Au}(111)$ (gray line), TMA-Mn (orange) and TMA-Mn after the addition of $10 \mathrm{mM}$ $\mathrm{H}_{2} \mathrm{O}_{2}$ (orange dashed line). Insets in the graphs show the different onset potentials for the shoulder at $-0.2 \mathrm{~V}$. Reprinted with permission from Ref. [100]. Copyright (C) 2013, Springer Nature

currents, however, faradaic currents generated during electrochemical reactions at the tip-electrolyte interface also need to be minimized during measurements, and currently, the most effective method is to insulate the tip immersed in solution by coating the entire tip except the apex of the tip end, which can effectively minimize faradaic currents through the reduction in the exposed tip area with respect to the electrolyte [103, 104].

Due to continuous efforts in the development of instruments and methodologies for EC-STM in in-situ and inoperando studies, EC-STM has become a set of indispensable experimental tools in the field of electrocatalysis for a wide range of reactions under harsh electrochemical conditions. The significance of EC-STM in the field of electrocatalysis began with the acquisition of atomic-resolution STM images of abundant single-crystal metals and metal alloys in electrolyte solutions [105-112], followed by the correlation of these potential-dependent surface structures to corresponding electrocatalytic properties. And with the further development of EC-STM, deeper understandings of key properties relating surface structures to electrocatalytic properties including surface adsorbate sites, activity, selectivity and stability can be acquired, all of which can greatly benefit the optimization and design of desirable electrocatalyst materials.

\subsection{Metal Surfaces and Their Alloys}

Earth-abundant $\mathrm{Cu}$ has received tremendous attention in the electrochemical reduction of $\mathrm{CO}_{2}$ because it can produce 
more reduced products such as hydrocarbons and oxygenates that require more than two-electron reduction due the intermediate binding energy of $\mathrm{Cu}$ for $\mathrm{CO}[113,114]$. Here, EC-STM is an important tool in the identification of the electrochemical properties of the different facets and surface structures of $\mathrm{Cu}$ metal. For example, Hahn et al. [115] used EC-STM to identify the atomic structures of three different $\mathrm{Cu}$ surfaces, including $\mathrm{Cu}(111), \mathrm{Cu}(100)$ and $\mathrm{Cu}(751)$, in which combined with electrochemical $\mathrm{CO}_{2}$ reduction tests, these researchers found experimental evidence that $\mathrm{Cu}(100)$ and $\mathrm{Cu}(751)$ surfaces were both more active and selective for $\mathrm{C}-\mathrm{C}$ coupling than $\mathrm{Cu}(111)$ and that the $\mathrm{Cu}(751)$ surface was the most selective for $>2 \mathrm{e}^{-}$oxygenate formation at lower overpotentials. Baricuatro et al. [116, 117] also used a combination of EC-STM with differential electrochemical mass spectroscopy (DEMS) to demonstrate that $\mathrm{CO}$ was only adsorbed at potentials more negative than $-0.8 \mathrm{~V}$ to form a fully vertical $\mathrm{c}(2 \times 2)$ structure (Fig. 6). In another example, Bae et al. [118] applied EC-STM to study nitrate adsorption and reduction on $\mathrm{Cu}(100)$ and foundthat nitrate ions formed a $(2 \times 2)$ adlattice from the open-circuit potential to $-0.22 \mathrm{~V}$ versus $\mathrm{Ag} / \mathrm{AgCl}$ on $\mathrm{Cu}(100)$ surfaces, but a predominant $\mathrm{c}(2 \times 2)$ structure from -0.25 to $-0.36 \mathrm{~V}$.

Alloying, especially surface alloying, with low-cost metals can decrease precious metal loading in corresponding materials and greatly benefit large-scale industrial applications. In addition, alloying can allow for the tuning of surface properties related to species adsorption, surface activity, selectivity and stability in which EC-STM is playing an increasingly important role in revealing these surface-related properties. For example, abundant metal alloys on noble metal surfaces such as $\mathrm{Cd} / \mathrm{Au}, \mathrm{Cu} / \mathrm{Au}$ and $\mathrm{Pd} / \mathrm{Au}$ on $\mathrm{Au}$ surfaces have been intensively investigated using EC-STM in terms of both synthesis by electrode position [119-125] and corresponding adsorption behaviors toward reactive species [126-130].

\subsection{Metal-Supported Organic Molecule-Based Electrocatalysts}

EC-STM has also been recognized as a powerful tool for the in situ study of organic molecule-based electrocatalysts supported by noble metal surfaces in terms of both essential properties including formation and structure and electrocatalytic properties. And to date, numerous studies have been conducted on organic molecule-based structures using EC-STM, not only in the field of electrocatalysis, but also in other applications such as gas sensors, optoelectronic devices, field effect transistors and solar cells [131-141]. Due to the focus of this review, however, this section will focus on electrocatalysis-related studies carried out using EC-STM. For example, Yoshimoto et al. [142] used a combination of CV measurements and EC-STM (in a benzene solution, $0.1 \mathrm{M} \mathrm{HClO}_{4}$ ) to demonstrate that in electrochemical ORR, iron octaethylporphyrin (FeOEP)/Au(111) enabled the two-step four-electron reduction of $\mathrm{O}_{2}$ to $\mathrm{H}_{2} \mathrm{O}$, whereas cobalt octaethylporphyrin (CoOEP)/Au(111) enabled the two-electron reduction of $\mathrm{O}_{2}$ to $\mathrm{H}_{2} \mathrm{O}$ in which in situ
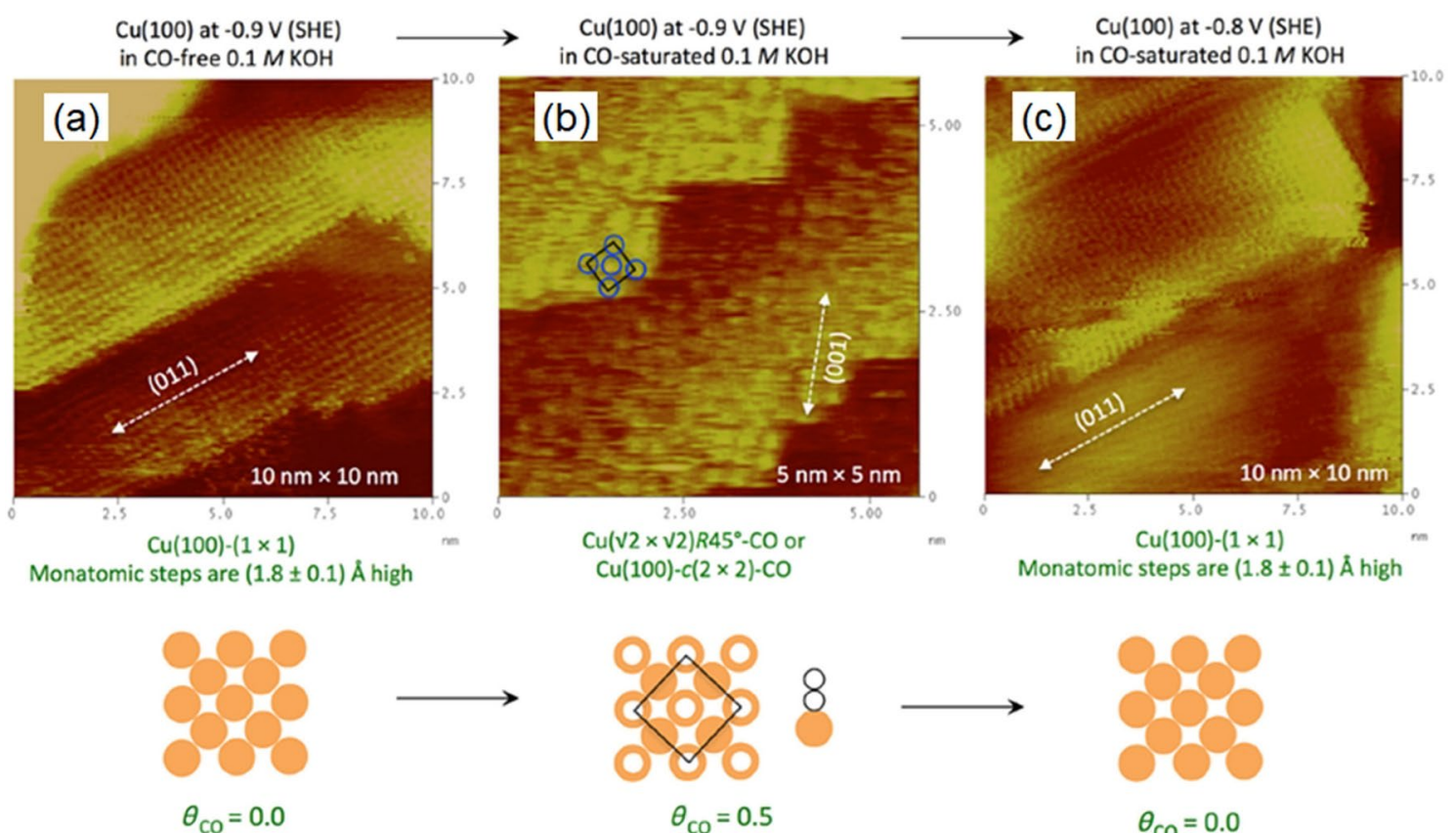

Fig. 6 EC-STM images of $\mathrm{Cu}(100)$ in $0.1 \mathrm{M} \mathrm{KOH}$ at $-0.9 \mathrm{~V}(\mathbf{a}, \mathbf{b})$ and $-0.8 \mathrm{~V}(\mathbf{c})$, with $(\mathbf{b}, \mathbf{c})$ and without (a) CO in solution. The adsorption of $\mathrm{CO}$ on $\mathrm{Cu}(100)$ is schematically illustrated in the bottom panel. Reprinted with permission from Ref. [116]. (C) 2018 Elsevier B.V 
EC-STM measurements revealed the formation of a highly ordered adlayer of FeOEP on the reconstructed $\mathrm{Au}(111)$ surface during the first electrochemical reduction of $\mathrm{O}_{2}$ to $\mathrm{H}_{2} \mathrm{O}_{2}$ and that under more negative electrode potentials, $\mathrm{H}_{2} \mathrm{O}_{2}$ can be further reduced to $\mathrm{H}_{2} \mathrm{O}$. Here, the in situ EC-STM images of this reaction suggested that FeOEP molecules on the terrace possessed high mobility based on the unclear surface morphology.

EC-STM can also be used to conduct the single-molecule imaging of adsorbates on electrocatalysts under solution conditions at liquid-solid interfaces in individual metal porphyrin molecules on metal substrates [143-146]. For example, Hulsken et al. [143] were able to demonstrate by capturing high-resolution STM images in a liquid cell with and without $\mathrm{O}_{2}$ and recording ultraviolet-visible (UV-Vis) solution spectra that oxygen atoms in $\mathrm{O}_{2}$ molecules were bound to adjacent porphyrin catalysts on the surface before incorporation into alkene substrates. Den Boer et al. [147] also used EC-STM to reveal the multi-step reaction of individual manganese porphyrin molecules on graphite with molecular oxygen at the solid/liquid interface in which at least four distinct reaction species with different configurations in the STM image were identified with their reaction dynamics being observed and revealed by EC-STM at the liquid/solid interface and under different gas environments.

Numerous electrocatalytic processes involving metal porphyrins under varying electrode potentials have also been revealed using in situ EC-STM [148-150]. For example, Wang et al. [148] obtained high-resolution STM images under saturated $\mathrm{O}_{2}$, air and $\mathrm{N}_{2}$ and were able to identify the in termediates of FePc- $\mathrm{O}_{2}$ and bare FePc monolayer on $\mathrm{Au}(111)$ based on the appearance of bright and dim points (Fig. 7a). And based on the reversible switch between FePc$\mathrm{O}_{2}$ and $\mathrm{FePc}$ from substrate potentials of $350 \mathrm{mV}$ to $50 \mathrm{mV}$ (Fig. 7b), these researchers were also able to demonstrate the ORR process for $\mathrm{O}_{2}$ reduction to $\mathrm{H}_{2} \mathrm{O}_{2}$, which was further validated by theoretical calculations and $\mathrm{CV}$ measurements. In a more recent study, these researchers also found that the OER activity of a 5,10,15,20-tetraphenyl-21 H,23 H-porphyrin cobalt(II) (CoTPP)/Au(111) electrode can be enhanced by increasing the alkalinity of the electrolyte in $\mathrm{CV}$ tests, and by combining UV-Vis absorption spectra with in situ EC-STM, these researchers found that OER in alkaline media occurred through the formation of CoTPP-OH-species intermediates to CoTPP-O ${ }_{2}$ product [149].

\section{Others}

\subsection{High-Speed EC-STM}

The time required to acquire conventional EC-STM images is usually on the order of seconds or minutes and is much slower than the highly dynamic processes of electrochemical catalytic reactions that are in the millisecond range. As a result, increases in scanning speed can greatly aid in the recording of a wide range of important dynamic phenomena at electrochemical interfaces, such as electrode surface variation, adsorbate diffusion and surface species transition between reactants, intermediates and products, all of which are essential in the study of electrocatalytic mechanisms. To address this, Magnussen et al. [151, 152] demonstrated the use of high-speed EC-STM (also known as video EC-STM) in their study and used this technique to study the electrochemical deposition and dissolution of $\mathrm{Cu}(100)$ in diluted $\mathrm{HCl}$ solution in which the high time resolution and high stability of the video EC-STM as well as the fast data acquisition and processing systems, high-gain high-bandwidth tunneling current preamplifiers, rapid feedback electronics and better mechanical stability are all indispensable [153-156].

In the last two decades, great progress has been made to video EC-STM techniques to enable the study of a variety of adsorbate dynamics, mainly on noble metal surfaces. These direct microscopic observations of electrochemical processes either on electrode surfaces or on adsorbates at electrochemical interfaces can help in the interpretation of fundamental mechanisms of electrocatalytic reactions and electrochemical growth. For example, Matsushima et al. [157] took advantage of the high time resolution of video STM to monitor the surface structure of $\mathrm{Cu}(100)$ during HER in $0.1 \mathrm{M} \mathrm{HClO}_{4}$ solution and were able to find that during HER, $\mathrm{Cu}(100)$ can undergo surface reconstruction from an unconstructed surface to a stripe-like structure (parallel to the $\mathrm{Cu}$ lattice) in less than $0.1 \mathrm{~s}$, which can increase HER rates. Adsorbate dynamics, especially in the case of ordered halogen $(\mathrm{Cl}$ and $\mathrm{Br}) \mathrm{c}(2 \times 2)$ structures on $\mathrm{Cu}(100)$ and $\operatorname{Ag}(100)$ with low coverage of other adsorbate species, have also been intensively studied using high-speed ECSTM [158-164]. For example, Rahn et al. [162] obtained a sequence of video EC-STM images taken every $100 \mathrm{~ms}$ on an $\mathrm{Ag}(100)$ surface in $1 \mathrm{mM} \mathrm{HClO}_{4}$ and $1 \mathrm{mM} \mathrm{KBr}$ at -0.12 $V_{\mathrm{SCE}}(\mathrm{SCE}=$ saturated calomel electrode) and were able to directly record the spontaneous transition of sulfur adsorbate between surface sites and subsurface sites (Fig. 8).

\subsection{Scanning Noise Microscopy}

Scanning noise microscopy (SNM) was developed to measure the noise parameters of tunneling current in STM and can be applied in monitoring dynamics at the nanoscale, especially in the case of molecular dynamics [165-168]. For example, Pfisterer et al. [169] used this technique in an electrochemical environment to directly reveal catalytically active surface sites under reaction conditions by monitoring relative changes in tunneling current noise. Here, these researchers proposed that tunneling 
(a)

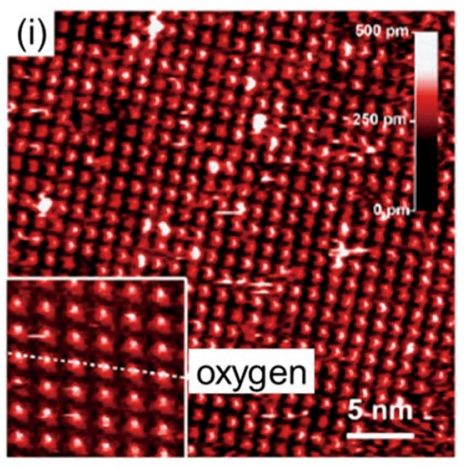

(iv) $n m$

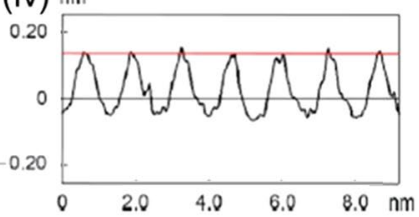

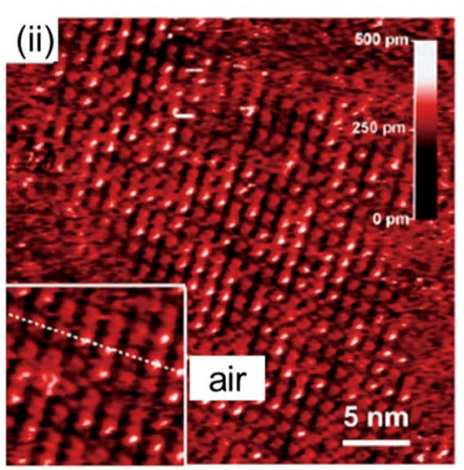

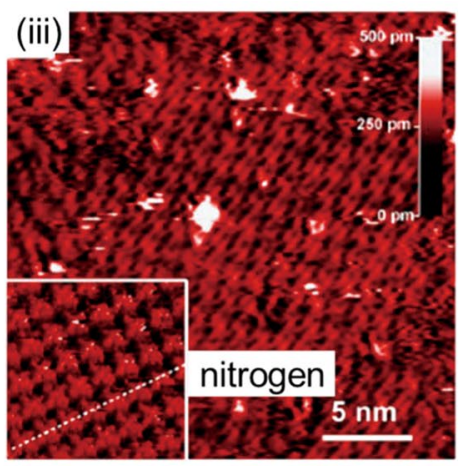

(v) $n m$

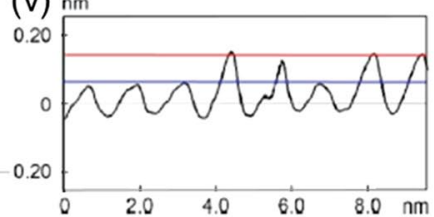

(vi) $\mathrm{nm}$

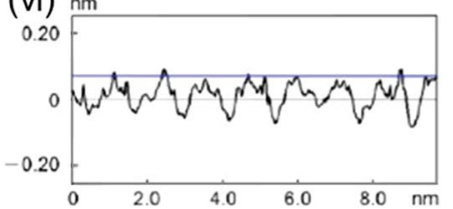

(b)

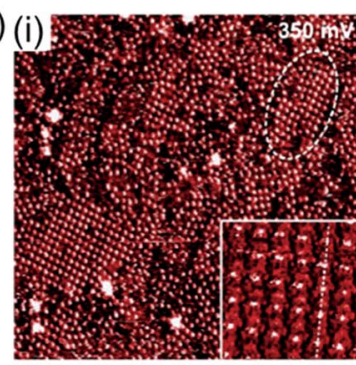

(v) $n m$
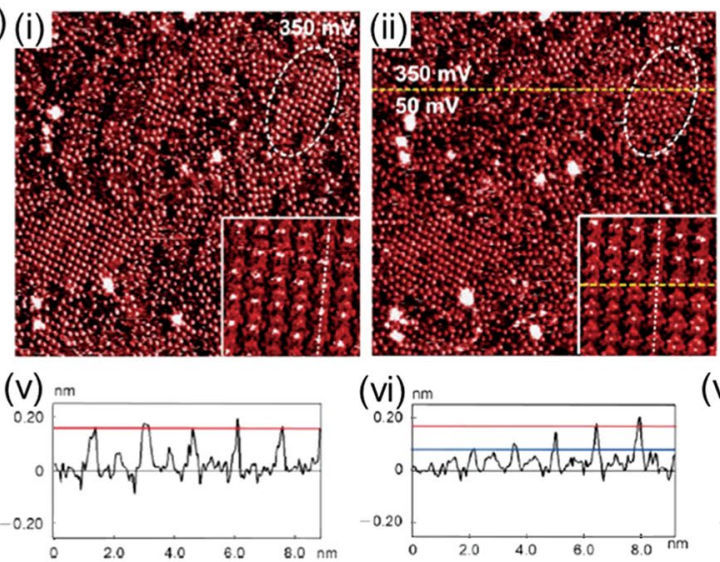

(vi) $\mathrm{nm}$

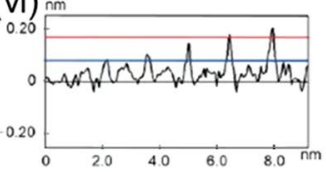

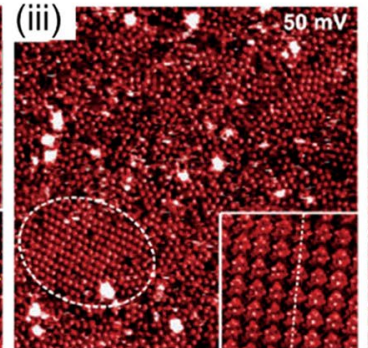

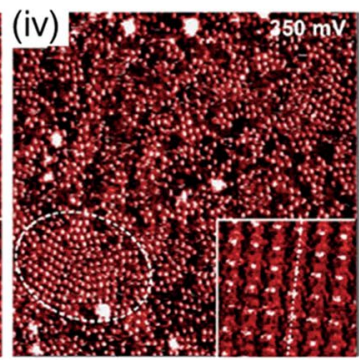

(vii)

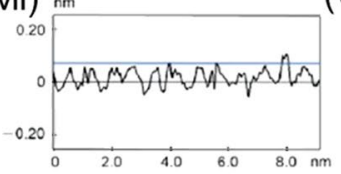

(viii)

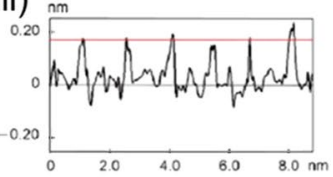

Fig. 7 a EC-STM images and height profiles of $\mathrm{FePc}$ on $\mathrm{Au}(111)$ under $0.1 \mathrm{M} \mathrm{HClO}_{4}$ saturated by (i) and (iv) oxygen, (ii) and (v) air and (iii) and (vi) nitrogen. Insets show enlarged STM images. b Sequential EC-STM images and height profiles of FePc monolayer on $\mathrm{Au}(111)$ in $0.1 \mathrm{M} \mathrm{HClO}_{4}$ saturated by oxygen at different potentials. Insets show the high-resolution STM images of FePc

currents under constant bias can vary with time on active sites (edge sites) as compared with those over nonactive sites (terrace sites), suggesting local catalytic processes (Fig. 9ai, ii). This concept was also demonstrated on $\operatorname{Pt}(111)$ surfaces (Fig. 9aiii, iv) in which the spatial noise of tunneling currents appeared on the step edge of Pt(111) under HER conditions to reveal that active HER sites were likely to be located at the step concavities of $\mathrm{Pt}$ electrodes. The high spatial resolution of this method was further demonstrated on a $\mathrm{Pd} / \mathrm{Au}(111)$ surface with more HER active Pd nanoislands being supported by less active $\mathrm{Au}(111)$ (Fig. 9b) in which if a working electrode potential was negative enough to initiate HER on Pd nanoislands but insufficient to do so on the less active $\mathrm{Au}(111)$ substrate, molecules. Yellow dotted lines in (ii) display the potential boundary. (i) and (v) $E=350 \mathrm{mV}, E_{\text {bias }}=-300.0 \mathrm{mV}$, (ii) and (vi) upper region: $E=350 \mathrm{mV}, E_{\text {bias }}=-300.0 \mathrm{mV}$, lower region: $E=50 \mathrm{mV}$, $E_{\text {bias }}=-300.0 \mathrm{mV}$, (iii) and (vii) $E=50 \mathrm{mV}, E_{\text {bias }}=-300.0 \mathrm{mV}$, (iv) and (viii) $E=350 \mathrm{mV}, E_{\text {bias }}=-300.0 \mathrm{mV}$. Reprinted with permission from Ref. [148]. Copyright (C 2016 American Chemical Society

noticeably higher noises were observed on the Pd nanoislands, especially near the Pd/Au boundary as compared with $\mathrm{Au}(111)$.

\subsection{Tip-Enhanced Raman Spectroscopy}

Tip-enhanced Raman spectroscopy (TERS) is an integrated system involving STM and Raman spectroscopy and possesses a sharp, plasmonically active and conducting tip in which through the use of plasmonic resonance raised by a sharp noble metal tip under an illumination laser, local electromagnetic fields near the tip apex can be strongly enhanced $[170,171]$. As a result, TERS can combine the sensitivity of Raman spectroscopy with the 

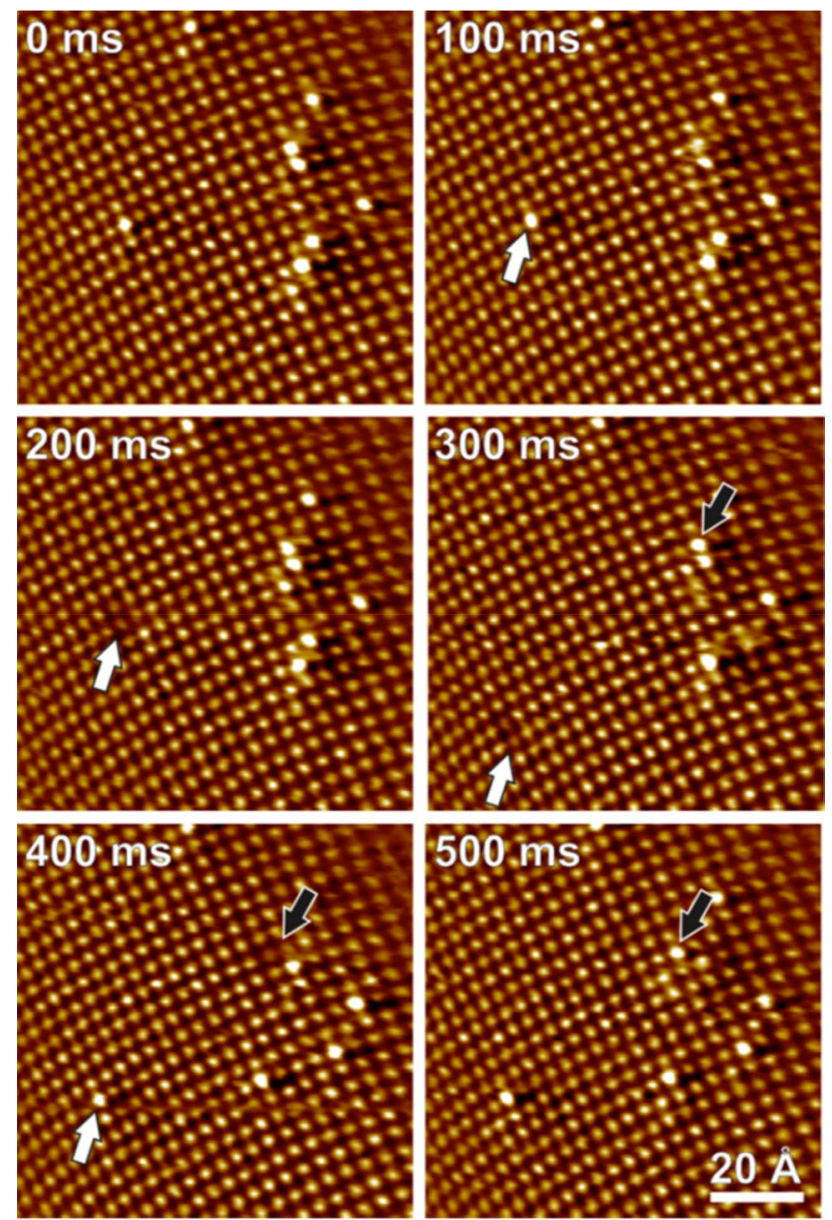

Fig. 8 Sequence of in situ video STM images obtained on $\operatorname{Ag}(100)$ electrodes in $1 \mathrm{mM} \mathrm{HClO}_{4}+1 \mathrm{mM} \mathrm{KBr}$ showing an ordered $\mathrm{c}(2 \times 2)$-Br lattice. Two sulfur adsorbates on the surface (bright protrusions) are indicated by white and black arrows. Reprinted with permission from Ref. [162]. Copyright (C) 2018 American Chemical Society

lateral resolution of scanning probe microscopy (SPM) and the sensitivity of surface-enhanced Raman spectroscopy (SERS), allowing for the nanoscale spatial resolution of Raman signals, particularly in UHV environments [172-175]. Because of this, TERS can probe individual surface molecule structures and their interaction with substrates at the nano/molecular scale, which is useful for the understanding of heterogeneous catalysis. In terms of application in the field of electrocatalysis, Nguyen et al. [176] were able to use UHV-TERS in their investigation of $\mathrm{O}_{2}$ adsorption on cobalt phthalocyanine $(\mathrm{CoPc}) / \mathrm{Ag}(111)$, which is the initial step of ORR. Zhong et al. [177] also achieved $3 \mathrm{~nm}$ resolution in the real space of TERS in ambient environments by using phenyl isocyanide (PIC) as a probing molecule on an atomically well-defined Pd(submonolayer)/Au(111) bimetallic model catalyst in which through the recording of the identical Raman peaks of PIC on the surface of $\mathrm{Pd} / \mathrm{Au}(111)$ (Fig. 10), these researchers were able to conclude that the $\mathrm{Pd} / \mathrm{Au}(111)$ surface exhibited significantly less activity toward the catalytic oxidation of PIC than the Au(111) surface under ambient conditions.

Compared with UHV and ambient environments, TERS operating under electrochemical environments can clearly provide more detailed and accurate information on interfacial processes and structures under electrode potentials [178-182]. For example, Zeng et al. [179] reported a STMbased EC-TERS with its laser introduced horizontally into an EC cell through a long working distance microscope objective to illuminate the gap between the tip and sample surface (sample tilted by $10^{\circ}$ ) (Fig. 11a). As a result, a strong TERS signal on 4'-(pyridin-4-yl)biphenyl-4-yl)methanethiol (4-PBT)/Au(111) appeared and disappeared as the tip approached and retracted, respectively. These potentialdependent EC-TERS data with the additional Raman peaks as compared with SERS (Fig. 11b) were subsequently successfully applied to reveal the molecular configuration of 4-PBT on Au(111). By using EC-TERS, Kurouski et al. [180] were also able to observe steplike behaviors in TERS voltammograms that reflected the electrochemical reduction and oxidation of single or few Nile blue (NB) molecules.

\section{Summary and Perspective}

STM is gaining increasing attention in the field of electrocatalysis and its ability to providing high-resolution information on surface structures, configurations and dynamics of surface adsorbates can significantly advance the fundamental understanding of electrocatalysts and electrocatalytic mechanisms, all of which are valuable for the rational optimization and design of excellent electrocatalysts. In this review, developments related to the study of electrocatalysts and electrochemistry using UHV-STM, EC-STM, high-speed EC-STM, SNM and TERS have been presented. And although challenges remain, research involving the application of these powerful techniques is rapidly growing and perspectives regarding UHV-STM and EC-STM can be listed as follows.

1. UHV-STM can provide atomic-resolution images of electrocatalyst surface structures that are highly important in the interpretation of electrocatalytic mechanisms because electrocatalytic reactions are atomic processes. And as compared with electron microscopy, STM can not only provide atomic-resolution images, but also provide information on local surface electronic structures through scanning tunneling spectroscopy (also known as $\mathrm{d} I / \mathrm{d} V$ curves), which is critical 
Fig. 9 a Revealing catalytic sites under reaction conditions using scanning noise microscopy. (i, ii) Schematic illustrations explaining the concept of using scanning noise microscopy to identify active sites showing that tunneling current noises change as local environments between STM tips and samples change (over a terrace, i, versus a step, ii, in the sample); (iii) STM line scans obtained over a $\mathrm{Pt}(111)$ surface in $0.1 \mathrm{M} \mathrm{HClO}_{4}$ if the potential of the sample is either sufficiently negative or too positive to initiate HER; (iv) typical STM line scans over a $\mathrm{Pt}(111)$ surface in $0.1 \mathrm{M} \mathrm{HClO}_{4}$ under HER conditions. b STM characterization of nanostructured surfaces under HER conditions. (i) Monoatomically high islands of $\mathrm{Pd}$ on $\mathrm{Au}(111)$ surface (top) and height profiles of Pd (bottom) (constant-current mode); (ii) STM image of the boundary between a Pd island and an $\mathrm{Au}(111)$ substrate under HER conditions in $0.1 \mathrm{M}$ sulfuric acid (constant-height mode); (iii) detailed STM line scans for the case shown in (i; iv) statistical analysis of STM line scans shown in (iii), over $\mathrm{Au}, \mathrm{Pd}$ and $\mathrm{Au} / \mathrm{Pd}$ boundaries. Reprinted with permission from Ref. [169]. Copyright @ 2017 , Springer Nature (a)
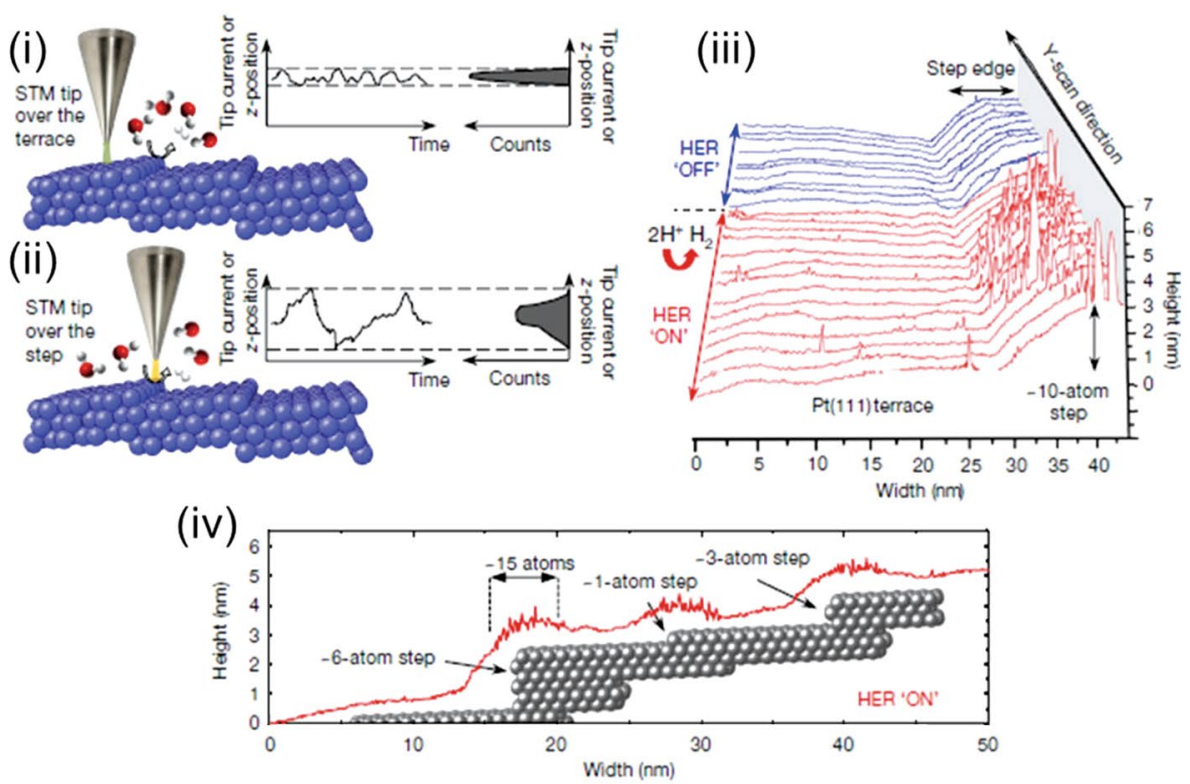

(b)
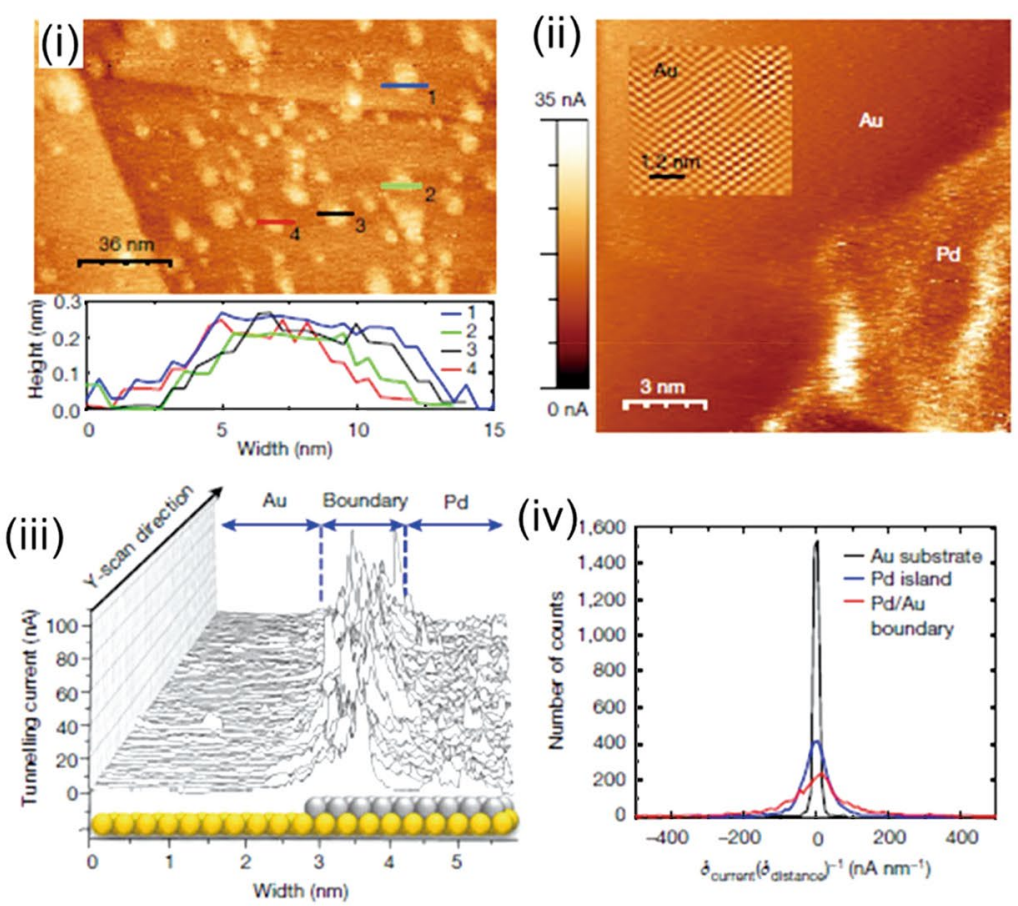

for the interpretation of electrocatalytic mechanisms, for example, by cooperating with the well-known $d$-band theory developed by Hammer and Nørskovto describe the adsorption strength between metals and adsorbates depending on the position of their $d$-bands [183]. In addition to surface electronic structures, the other unique aspect of STM is the ability to acquire the configurations and dynamics of surface adsorbates through the measurement of real space atoms and molecules on the surface. And although UHV-STM can deviate more from actual electrocatalytic reactions as compared with EC-STM operating in electrochemical environments due to vacuum conditions and the requirement for surface cleanness, the combination of obtained information with other characterizations and theoretical calculations can generate pioneering stud- 
(a)

(b)
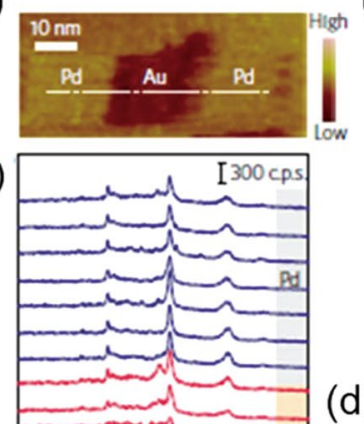

(d)
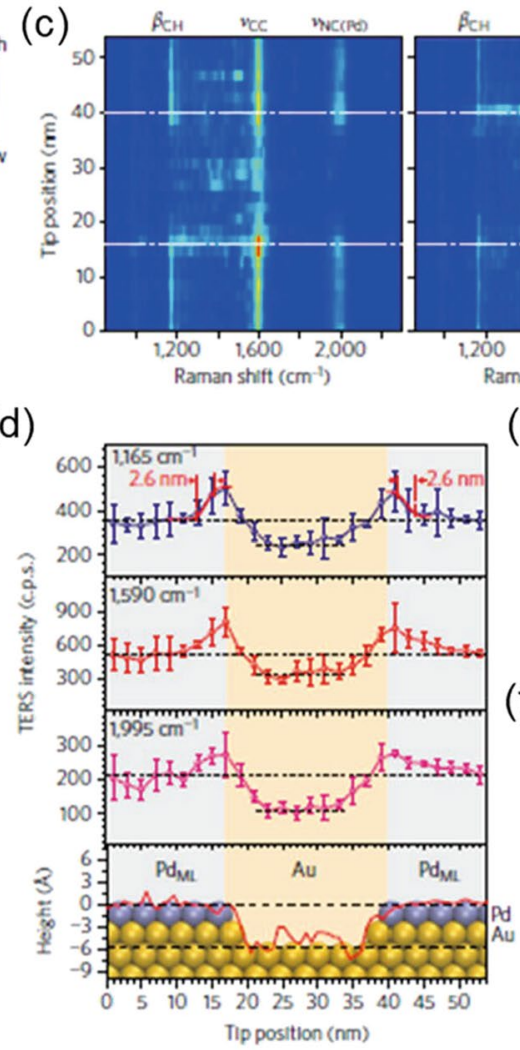
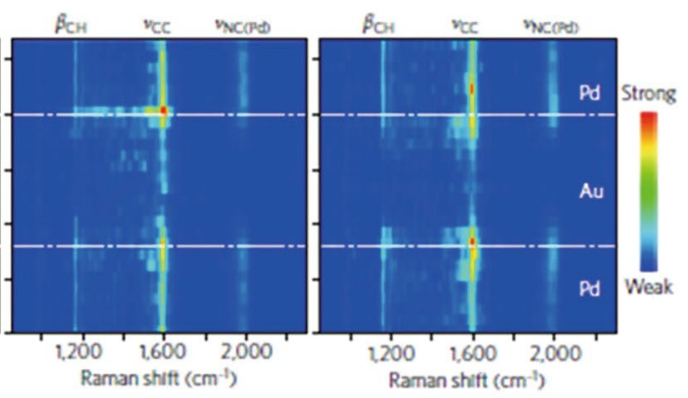

(e)

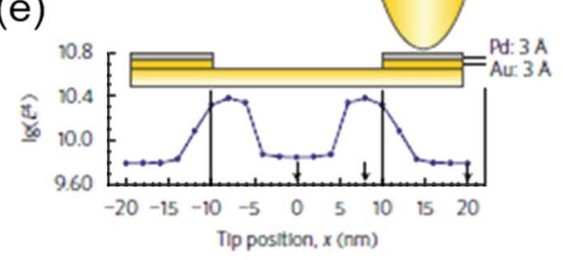

(f)

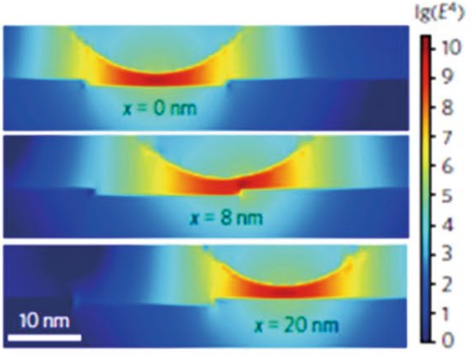

Fig. 10 TERS results for a $\mathrm{Pd} / \mathrm{Au}(111)$ bimetallic surface. a STM image of the Pd0.8ML/Au(111) surface. b Line-trace TERS spectra acquired along the dashed line in (a). c Color-coded intensity maps of three line-trace TERS images taken in succession. $\mathbf{d}$ Top three panels: intensity plots of the three main TERS peaks (1165, 1590 and $1995 \mathrm{~cm}^{-1}$ ) with respect to tip position. Bottom panel: topographic height profile of the surface along the dashed line in (a) superim- posed with the atomic model of the surface atoms. e Calculated TERS enhancement factor if an Au tip is located at different positions on a $\mathrm{Pd}-\mathrm{Au}-\mathrm{Pd}$ surface (top inset: substrate model for calculation). $\mathbf{f}$ Calculated TERS enhancement distribution on the $x-z$ plane if the tip occupies three different positions: Au $(x=0 \mathrm{~nm})$, step edge $(x=8 \mathrm{~nm})$ and Pd $(x=20 \mathrm{~nm})$ surface. Reprinted with permission from Ref. [177]. Copyright @ 2016 , Springer Nature ies of fundamental mechanisms and designs of novel catalyst systems.

2. EC-STM is a powerful and unusual tool for the in situ characterization of electrochemical interfaces and electrode processes in reaction environments because it can allow for the independent control of potentials at both the tip and working electrode. As a result, the obtained detailed information of electrode surfaces and adsorbate electrochemical processes under different working electrode potentials can allow for the direct recording of electrocatalytic reactions, which is highly advantageous as compared with STM operating in UHV or ambient environments. Because of this, EC-STM can provide indispensable insights into the fundamental mechanisms of electrocatalysis and electrochemistry.
Despite this, the application of EC-STM is limited by strict sample requirements including high cleanness, flatness and conductivity, making this technique more applicable for model catalyst systems. In addition, the application of EC-STM in the study of gas/solution/ solid interfaces is limited to a number of high-quality metal and metal alloy surfaces (or thin oxide islands and films supported by metals or metal alloys) and a limited number of gases. Here, theoretical simulations on electrocatalysts and electrochemical interfaces as well as characterizations using other in situ or in operando spectroscopic techniques such as Fourier transform infrared (FTIR), Raman and photoelectron spectroscopy (PES) can greatly assist EC-STM in revealing the properties of electrocatalysts and electrochemical mechanisms. 
Fig. 11 a EC-TERS system: (i) schematic illustration of the setup; (ii) SEM image of the insulated gold tip; (iii) microscopic image of the tip as it approaches the substrate with laser illumination; (iv) TERS spectra of 4-PBT adsorbed on $\mathrm{Au}(111)$ surface with the tip approaching (top) and retracting (bottom), respectively. b ECSTM and EC-TERS measurements on a 4-PBT-adsorbed $\mathrm{Au}(111)$ surface: (i) EC-STM image of the surface; (ii) CVs of bare (black) and 4-PBTadsorbed (red) $\mathrm{Au}(111)$ electrodes; (iii) potential-dependent EC-TERS spectra of a 4-PBT adsorbed on $\mathrm{Au}(111)$ surface; (iv) potential-dependent SERS spectra of a 4-PBT-modified Au NP surface. Reprinted with permission from Ref. [179]. Copyright () 2015 American Chemical Society (a)

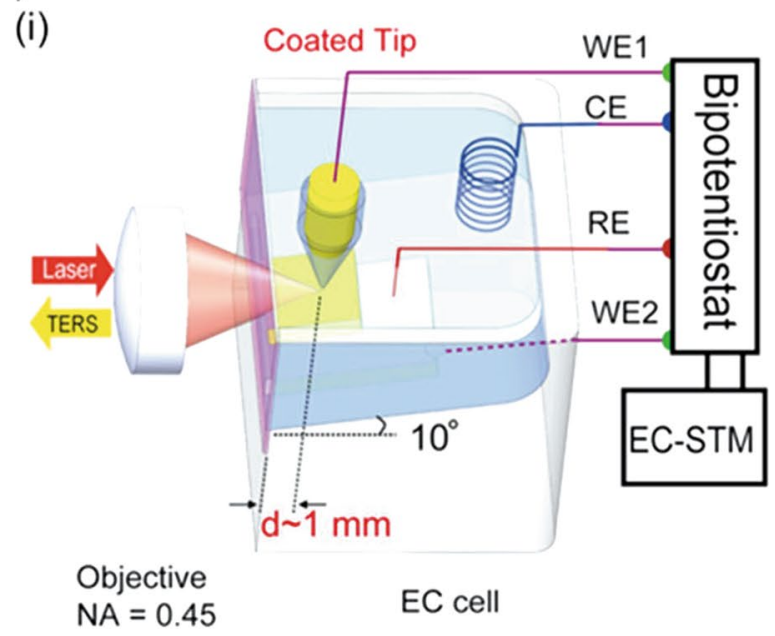

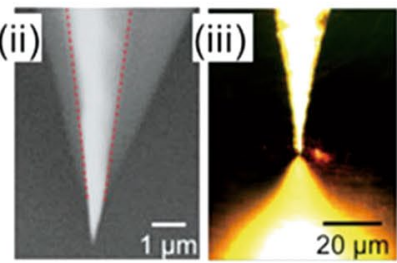

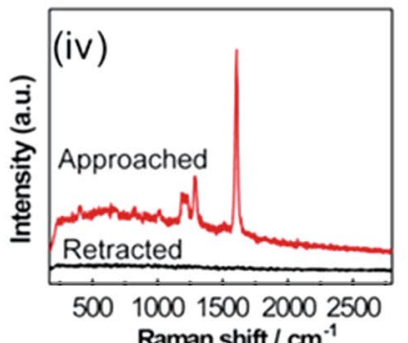

(b)
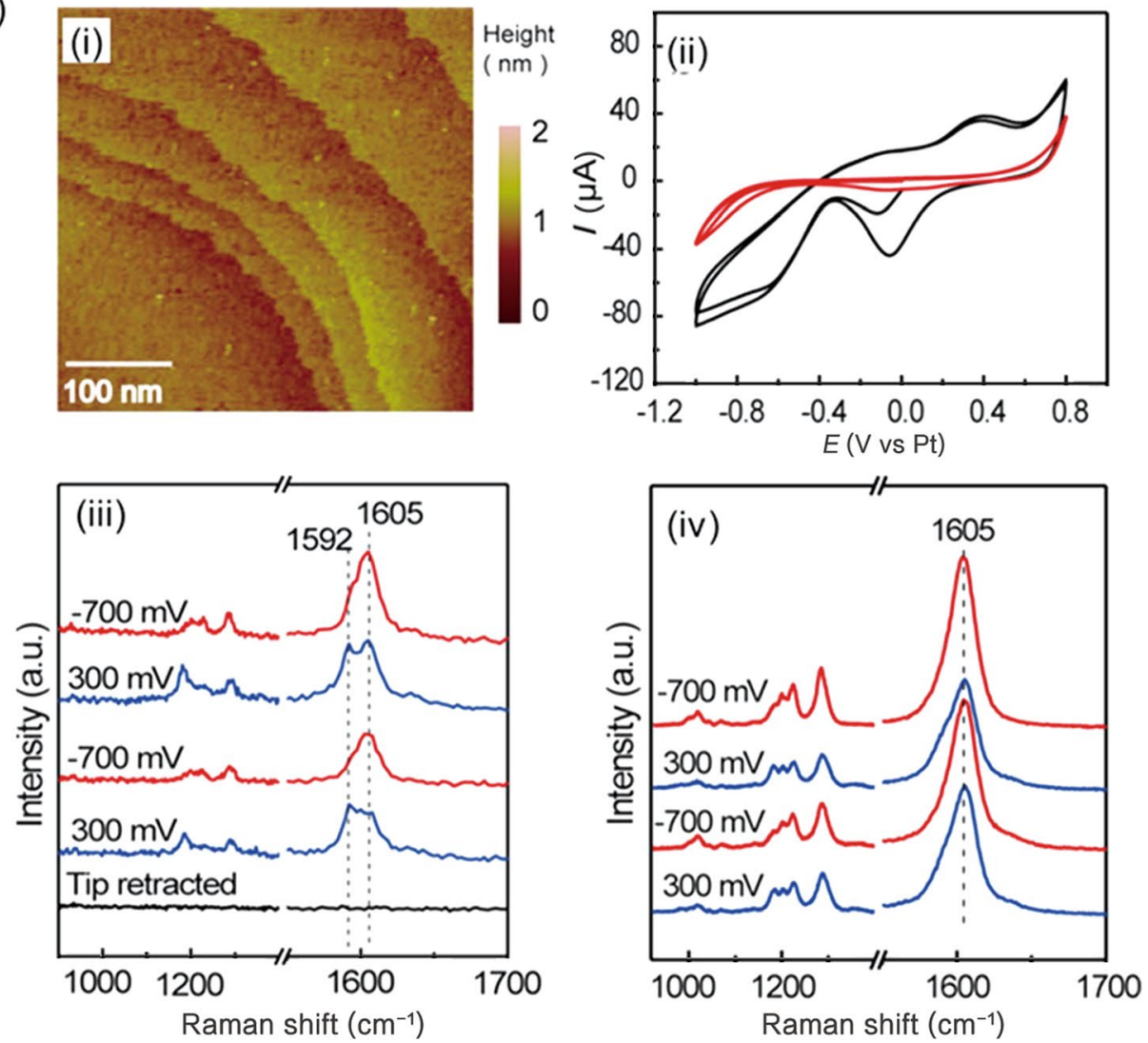

Acknowledgements This work was financially supported by the Australian Research Council (DP170101467, DP160102627 and FT180100585). The authors would also like to thank Dr. T. Silver for her valuable insights.

Open Access This article is licensed under a Creative Commons Attribution 4.0 International License, which permits use, sharing, adaptation, distribution and reproduction in any medium or format, as long as you give appropriate credit to the original author(s) and the source, provide a link to the Creative Commons licence, and indicate if changes were made. The images or other third party material in this article are included in the article's Creative Commons licence, unless indicated otherwise in a credit line to the material. If material is not included in the article's Creative Commons licence and your intended use is not permitted by statutory regulation or exceeds the permitted use, you will need to obtain permission directly from the copyright holder. To view a copy of this licence, visit http://creativecommons .org/licenses/by/4.0/. 


\section{References}

1. Seh, Z.W., Kibsgaard, J., Dickens, C.F., et al.: Combining theory and experiment in electrocatalysis: insights into materials design. Science 355, 4998 (2017)

2. Ross, M.B., Luna, P.D., Li, Y., et al.: Designing materials for electrochemical carbon dioxide recycling. Nat. Catal. 2, 648-658 (2019)

3. Debe, M.K.: Electrocatalyst approaches and challenges for automotive fuel cells. Nature 486, 43-51 (2012)

4. Guo, Y., Park, T., Yi, J.W., et al.: Nanoarchitectonics for transition-metal-sulfide-based electrocatalysts for water splitting. Adv. Mater. 31, 1807134 (2019)

5. Tan, H., Tang, J., Henzie, J., et al.: Assembly of hollow carbon nanospheres on graphene nanosheets and creation of ironnitrogen-doped porous carbon for oxygen reduction. ACS Nano 12, 5674-5683 (2018)

6. Xia, W., Tang, J., Li, J., et al.: Defect-rich graphene nanomesh produced by thermal exfoliation of metal-organic frameworks for the oxygen reduction reaction. Angew. Chem. 131, 1348813493 (2019)

7. Vang, R.T., Lauritsen, J.V., Lægsgaard, E., et al.: Scanning tunneling microscopy as a tool to study catalytically relevant model systems. Chem. Soc. Rev. 37, 2191-2203 (2008)

8. Stamenkovic, V.R., Strmcnik, D., Lopes, P.P., et al.: Energy and fuels from electrochemical interfaces. Nat. Mater. 16, 57-69 (2017)

9. Su, Z., Liu, J., Li, M., et al.: Defect engineering in titanium-based oxides for electrochemical energy storage devices. Electrochem. Energy Rev. 3, 286-343 (2020)

10. Wintterlin, J.: Scanning tunneling microscopy studies of catalytic reactions. Adv. Catal. 45, 131-206 (2000)

11. Reniers, F.: The development of a transfer mechanism between UHV and electrochemistry environments. J. Phys. D Appl. Phys. 35, R169-R188 (2002)

12. Schnaidt, J., Beckord, S., Engstfeld, A.K., et al.: A combined UHV-STM-flow cell set-up for electrochemical/electrocatalytic studies of structurally well-defined UHV prepared model electrodes. Phys. Chem. Chem. Phys. 19, 4166-4178 (2017)

13. Faisal, F., Stumm, C., Bertram, M., et al.: Electrifying model catalysts for understanding electrocatalytic reactions in liquid electrolytes. Nat. Mater. 17, 592-598 (2018)

14. Faisal, F., Bertram, M., Stumm, C., et al.: Preparation of complex model electrocatalystsin ultra-high vacuum and transfer into the electrolyte for electrochemical IR spectroscopy and other techniques. Rev. Sci. Instrum. 89, 114101 (2018)

15. Sonnenfeld, R., Hansma, P.K.: Atomic-resolution microscopy in water. Science 232, 211-213 (1986)

16. Itaya, K., Tomita, E.: Scanning tunneling microscope for electrochemistry - a new concept for the in situ scanning tunneling microscope in electrolyte solutions. Surf. Sci. 201, L507-L512 (1988)

17. Haiss, W., Lackey, D., Sass, J.K.: Atomic resolution scanning tunneling microscopy images of $\mathrm{Au}(111)$ surfaces in air and polar organic solvents. J. Chem. Phys. 95, 2193-2196 (1991)

18. Makri, M., Vayenas, C.G., Bebelis, S., et al.: Atomic resolution STM imaging of electrochemically controlled reversible promoter dosing of catalysts. Surf. Sci. 369, 351-359 (1996)

19. Gewirth, A.A., Niece, B.K.: Electrochemical applications of in situ scanning probe microscopy. Chem. Rev. 97, 1129-1162 (1997)

20. Jiang, P., Bao, X., Salmeron, M.: Catalytic reaction processes revealed by scanning probe microscopy. Acc. Chem. Res. 48, 1524-1531 (2015)
21. Vang, R.T., Lægsgaard, E., Besenbacher, F.: Bridging the pressure gap in model systems for heterogeneous catalysis with high-pressure scanning tunneling microscopy. Phys. Chem. Chem. Phys. 9, 3460-3469 (2007)

22. Cui, C.H., Yu, S.H.: Engineering interface and surface of noble metal nanoparticle nanotubes toward enhanced catalytic activity for fuel cell applications. Acc. Chem. Res. 467, 1427-1437 (2013)

23. Quan, Z., Wang, Y., Fang, J.: High-index facet noble metal nanocrystals. Acc. Chem. Res. 462, 191-202 (2013)

24. Toda, T., Igarashi, H., Uchida, H., et al.: Enhancement of the electroreduction of oxygen on $\mathrm{Pt}$ alloys with $\mathrm{Fe}, \mathrm{Ni}$, and Co. J. Electrochem. Soc. 146, 3750-3756 (1999)

25. Yu, W., Porosoff, M.D., Chen, J.G.: Review of Pt-based bimetallic catalysis: from model surfaces to supported catalysts. Chem. Rev. 112, 5780-5817 (2012)

26. Li, M., Duanmu, K., Wan, C.: Single-atom tailoring of platinum nanocatalysts for high-performance multifunctional electrocatalysis. Nat. Catal. 2, 495-503 (2019)

27. Luo, M., Zhao, Z., Zhang, Y., et al.: PdMo bimetallene for oxygen reduction catalysis. Nature 574, 81-85 (2019)

28. Paulus, U.A., Wokaun, A., Scherer, G.G.: Oxygen reduction on carbon-supported Pt-Ni and Pt-Co alloy catalysts. J. Phys. Chem. B 106, 4181-4191 (2002)

29. Stamenković, V., Schmidt, T.J., Ross, P.N., et al.: Surface composition effects in electrocatalysis: kinetics of oxygen reduction on well-defined $\mathrm{Pt}_{3} \mathrm{Ni}$ and $\mathrm{Pt}_{3} \mathrm{Co}$ alloy surfaces. J. Phys. Chem. B 106, 11970-11979 (2002)

30. Stamenković, V., Mun, B.S., Mayrhofer, K.J.J., et al.: Changing the activity of electrocatalysts for oxygen reduction by tuning the surface electronic structure. Angew. Chem. Int. Ed. 45, 2897-2901 (2006)

31. Stamenković, R.V., Fowler, B., Mun, B.S., et al.: Improved oxygen reduction activity on $\mathrm{Pt}_{3} \mathrm{Ni}(111)$ via increased surface site availability. Science 315, 493-497 (2007)

32. Yang, X., Hu, J., Fu, J., et al.: Role of surface iron in enhanced activity for the oxygen reduction reaction on a $\mathrm{Pd}_{3} \mathrm{Fe}(111)$ single-crystal alloy. Angew. Chem. Int. Ed. 50, 10182-10185 (2011)

33. Yang, X., Koel, B.E., Wang, H., et al.: Nanofaceted C/Re(11-21): fabrication, structure, and template for synthesizing nanostructured model Pt electrocatalyst for hydrogen evolution reaction. ACS Nano 6, 1404-1409 (2012)

34. Wang, H., Chen, W., Bartynski, R.A., et al.: Nitrogen-induced reconstruction and faceting of $\operatorname{Re}(11-21)$. J. Chem. Phys. 140, 024707 (2014)

35. Todoroki, N., Iijima, Y., Takahashi, R., et al.: Structure and electrochemical stability of Pt-enriched Ni/Pt(111) topmost surface prepared by molecular beam epitaxy. J. Electrochem. Soc. 160, F591-F596 (2013)

36. Iijima, Y., Kondo, T., Takahashi, Y., et al.: Oxygen reduction reaction activities for $\mathrm{Pt} / \mathrm{Au}(\mathrm{hkl})$ bimetallic surfaces prepared by molecular beam epitaxy. J. Electrochem. Soc. 160, F898-F904 (2013)

37. Todoroki, N., Asakimori, Y., Wadayama, T.: Effective shell layer thickness of platinum for oxygen reduction reaction alloy catalysts. Phys. Chem. Chem. Phys. 15, 17771-17774 (2013)

38. Todoroki, N., Dasai, T., Asakimori, Y., et al.: Microscopic surface structures and ORR activities for vacuum-deposited Pt/Ni/ $\mathrm{Pt}(111)$ and $\mathrm{Pt} / \mathrm{Ni} / \mathrm{Pt}(110)$ sandwich structures. J. Electroanal. Chem. 724, 15-20 (2014)

39. Bando, Y., Takahashi, Y., Ueta, E., et al.: Electrochemical properties of Pt epitaxial layers formed on $\mathrm{Pd}(111)$ in ultra-high vacuum. J. Electrochem. Soc. 162, F463-F467 (2015)

40. Asano, M., Kawamura, R., Sasakawa, R., et al.: Oxygen reduction reaction activity for strain-controlled Pt-based model alloy 
catalysts: surface strains and direct electronic effects induced by alloy elements. ACS Catal. 6, 5285-5289 (2016)

41. Todoroki, N., Yokota, N., Nakahata, S., et al.: Electrochemical reduction of $\mathrm{CO}_{2}$ on $\mathrm{Ni}$ - and Pt-epitaxially grown $\mathrm{Cu}(111)$ surfaces. Electrocatalysis 7, 97-103 (2016)

42. Todoroki, N., Tei, H., Tsurumaki, H., et al.: Surface atomic arrangement dependence of electrochemical $\mathrm{CO}_{2}$ reduction on gold: online electrochemical mass spectrometric study on lowindex Au(hkl) surfaces. ACS Catal. 92, 1383-1388 (2019)

43. Todoroki, N., Tei, H., Miyakawa, T., et al.: Electrochemical $\mathrm{CO}_{2}$ reduction on bimetallic surface alloys: enhanced selectivity to $\mathrm{CO}$ for $\mathrm{Co} / \mathrm{Au}(110)$ and to $\mathrm{H}_{2}$ for $\mathrm{Sn} / \mathrm{Au}(110)$. ChemElectroChem 6, 3101-3107 (2019)

44. Song, F., Bai, L., Moysiadou, A., et al.: Transition metal oxides as electrocatalysts for the oxygen evolution reaction in alkaline solutions: an application-inspired renaissance. J. Am. Chem. Soc. 140, 7748-7759 (2018)

45. Jamesh, M.-I., Sun, X.: Recent progress on earth abundant electrocatalysts for oxygen evolution reaction (OER) in alkaline medium to achieve efficient water splitting - a review. J. Power Sources 400, 31-68 (2018)

46. Wang, H., Lee, H.-W., Deng, Y., et al.: Bifunctional non-noble metal oxide nanoparticle electrocatalysts through lithiuminduced conversion for overall water splitting. Nat. Commun. 6, $7261(2015)$

47. Yan, X., Tian, L., He, M., et al.: Three-dimensional crystalline/ amorphous $\mathrm{Co} / \mathrm{Co}_{3} \mathrm{O}_{4}$ core/shell nanosheets as efficient electrocatalysts for the hydrogen evolution reaction. Nano Lett. 15, 6015-6021 (2015)

48. Pei, D.N., Gong, L., Zhang, A.-Y., et al.: Defective titanium dioxide single crystals exposed by high-energy 001 facets for efficient oxygen reduction. Nat. Commun. 6, 8696 (2015)

49. Osgood, H., Devaguptapu, S.V., Xu, H., et al.: Transition metal ( $\mathrm{Fe} \mathrm{Co}, \mathrm{Ni}$, and $\mathrm{Mn}$ ) oxides for oxygen reduction and evolution bifunctional catalysts in alkaline media. Nano Today 11, 601-625 (2016)

50. Qiu, J., Li, S., Gray, E., et al.: Hydrogenation synthesis of blue $\mathrm{TiO}_{2}$ for high-performance lithium-ion batteries. J. Phys. Chem. C 118, 8824-8830 (2014)

51. Mu, R., Zhao, Z.J., Dohnálek, Z., et al.: Structural motifs of water on metal oxide surfaces. Chem. Soc. Rev. 46, 1785-1806 (2017)

52. Pang, C.L., Lindsay, R., Thornton, G.: Structure of clean and adsorbate-covered single-crystal rutile $\mathrm{TiO}_{2}$ surfaces. Chem. Rev. 113, 3887-3948 (2013)

53. Feng, H., Xu, Z., Ren, L., et al.: Activating titania for efficient electrocatalysis by vacancy engineering. ACS Catal. 8, 42884293 (2018)

54. Freund, H.J., Pacchioni, G., et al.: Oxide ultra-thin films on metals: new materials for the design of supported metal catalysts. Chem. Soc. Rev. 37, 2224-2242 (2008)

55. Surnev, S., Fortunelli, A., Netzer, F.P.: Structure-property relationship and chemical aspects of oxide-metal hybrid nanostructures. Chem. Rev. 113, 4314-4372 (2013)

56. Schoiswohl, J., Sock, M., Chen, Q., et al.: Metal supported oxide nanostructures: model systems for advanced catalysis. Top. Catal. 46, 137-149 (2007)

57. Guimond, S., Haija, M.A., Kaya, S., et al.: Vanadium oxide surfaces and supported vanadium oxide nanoparticles. Top. Catal. 38, 117-125 (2006)

58. Yang, F., Graciani, J., Evans, J., et al.: CO oxidation on inverse $\mathrm{CeO}_{\mathrm{x}} / \mathrm{Cu}(111)$ catalysts: high catalytic activity and ceria-promoted dissociation of $\mathrm{O}_{2}$. J. Am. Chem. Soc. 133, 3444-3451 (2011)
59. Yao, Y., Fu, Q., Wang, Z., et al.: Growth and characterization of two-dimensional $\mathrm{FeO}$ nanoislands supported on Pt(111). J. Phys. Chem. C 114, 17069-17079 (2010)

60. Merte, L.R., Shipilin, M., Ataran, S., et al.: Growth of ultrathin iron oxide films on $\operatorname{Ag}(100)$. J. Phys. Chem. C 119, 2572-2582 (2015)

61. Zhao, G., Yang, F., Chen, Z., et al.: Metal/oxide interfacial effects on the selective oxidation of primary alcohols. Nat. Commun. 8 , 14039 (2017)

62. Zeuthen, H., Kudernatsch, W., Merte, L.R., et al.: Unraveling the edge structures of platinum(111)-supported ultrathin $\mathrm{FeO}$ islands: the influence of oxidation state. ACS Nano 9, 573-583 (2015)

63. Li, Y., Adamsen, K.C., Lammich, L., et al.: Atomic-scale view of the oxidation and reduction of supported ultrathin $\mathrm{FeO}$ islands. ACS Nano 13, 11632-11641 (2019)

64. Heinz, K., Hammer, L.: Epitaxial cobalt oxide films on $\operatorname{Ir}(100)$ the importance of crystallographic analyses. J. Phys. Condens. Matter 25, 173001 (2013)

65. Li, M., Altman, E.I.: Shape, morphology, and phase transitions during Co oxide growth on Au(111). J. Phys. Chem. C 118, 12706-12716 (2014)

66. Walton, A.S., Fester, J., Bajdich, M., et al.: Interface controlled oxidation states in layered cobalt oxide nanoislands on gold. ACS Nano 9, 2445-2453 (2015)

67. Fester, J., García-Melchor, M., Walton, A.S., et al.: Edge reactivity and water-assisted dissociation on cobalt oxide nanoislands. Nat. Commun. 8, 14169 (2017)

68. Fester, J., Makoveev, A., Grumelli, D., et al.: The structure of the cobalt oxide/Au catalyst interface in electrochemical water splitting. Angew. Chem. Int. Ed. 57, 11893-11897 (2018)

69. Hinnemann, B., Moses, P.G., Bonde, J., et al.: Biomimetic hydrogen evolution: $\mathrm{MoS}_{2}$ nanoparticles as catalyst for hydrogen evolution. J. Am. Chem. Soc. 127, 5308-5309 (2005)

70. Jaramillo, T.F., Jørgensen, K.P., Bonde, J., et al.: Identification of active edge sites for electrochemical $\mathrm{H}_{2}$ evolution from $\mathrm{MoS}_{2}$ nanocatalysts. Science 317, 100-102 (2007)

71. Ye, L., Wu, C., Guo, W., et al.: $\mathrm{MoS}_{2}$ hierarchical hollow cubic cages assembled by bilayers: one-step synthesis and their electrochemical hydrogen storage properties. Chem. Commun. 45, 4738-4740 (2006)

72. Li, Y., Wang, H., Xie, L., et al.: $\mathrm{MoS}_{2}$ nanoparticles grown on graphene: an advanced catalyst for the hydrogen evolution reaction. J. Am. Chem. Soc. 133, 7296-7299 (2011)

73. Lukowski, M.A., Daniel, A.S., Meng, F., et al.: Enhanced hydrogen evolution catalysis from chemically exfoliated metallic $\mathrm{MoS}_{2}$ nanosheets. J. Am. Chem. Soc. 135, 2810274-2810277 (2013)

74. Wu, Z., Fang, B., Wang, Z., et al.: $\mathrm{MoS}_{2}$ nanosheets: a designed structure with high active site density for the hydrogen evolution reaction. ACS Catal. 3, 2101-2107 (2013)

75. Jaramillo, T.F., Bonde, J., Zhang, J., et al.: Hydrogen evolution on supported incomplete Cubane-type $\left[\mathrm{Mo}_{3} \mathrm{~S}_{4}\right]^{4+}$ electrocatalysts. J. Phys. Chem. C 112, 17492-17498 (2008)

76. Kibsgaard, J., Jaramillo, T.F., Besenbacher, F.: Building an appropriate active-site motif into a hydrogen-evolution catalyst with thiomolybdate $\left[\mathrm{Mo}_{3} \mathrm{~S}_{13}\right]^{2-}$ clusters. Nat. Chem. 6, 248-253 (2014)

77. Huang, Z., Luo, W., Ma, L., et al.: Dimeric $\left[\mathrm{Mo}_{2} \mathrm{~S}_{12}\right]^{2-}$ cluster: a molecular analogue of $\mathrm{MoS}_{2}$ edge for superior hydrogen-evolution electrocatalysis. Angew. Chem. Int. Ed. 54, 15181-15185 (2015)

78. Li, H., Tsai, C., Koh, A.L., et al.: Activating and optimizing $\mathrm{MoS}_{2}$ basal planes for hydrogen evolution through the formation of strained sulphur vacancies. Nat. Mater. 15, 48-53 (2016) 
79. Chen, Y., Huang, S., Ji, X., et al.: Tuning electronic structure of single layer $\mathrm{MoS}_{2}$ through defect and interface engineering. ACS Nano 12, 2569-2579 (2018)

80. Barja, S., Refaely-Abramson, S., Schuler, B., et al.: Identifying substitutional oxygen as a prolific point defect in monolayer transition metal dichalcogenides. Nat. Commun. 10, 3382 (2019)

81. Petô, J., Ollár, T., Vancsó, P., et al.: Spontaneous doping of the basal plane of $\mathrm{MoS}_{2}$ single layers through oxygen substitution under ambient conditions. Nat. Chem. 10, 1246-1251 (2018)

82. Seok, J., Lee, J.H., Cho, S., et al.: Active hydrogen evolution through lattice distortion in metallic $\mathrm{MoTe}_{2}$. 2D Mater. 4, 025061 (2017)

83. Zhu, J., Wang, Z.C., Dai, H., et al.: Boundary activated hydrogen evolution reaction on monolayer $\mathrm{MoS}_{2}$. Nat. Commun. 10, 1348 (2019)

84. Shi, J., Ji, Q., Liu, Z., et al.: Recent advances in controlling syntheses and energy related applications of $\mathrm{MX}_{2}$ and $\mathrm{MX}_{2}$ /graphene heterostructures. Adv. Energy Mater. 6, 1600459 (2016)

85. Feng, H., Xu, Z., Zhuang, J., et al.: Role of charge density wave in monatomic assembly in transition metal dichalcogenides. Adv. Funct. Mater. 29, 1900367 (2019)

86. Vancsó, P., Popov, Z.I., Petô, J., et al.: Transition metal chalcogenide single layers as an active platform for single-atom catalysis. ACS Energy Lett. 4, 1947-1953 (2019)

87. Bedioui, F., Griveau, S., Nyokong, T.: Tuning the redox properties of metalloporphyrin-and metallophthalocyanine-based molecular electrodes for the highest electrocatalytic activity in the oxidation of thiols. Phys. Chem. Chem. Phys. 9, 3383-3396 (2007)

88. Costentin, C., Drouet, S., Robert, M., et al.: A local proton source enhances $\mathrm{CO}_{2}$ electroreduction to $\mathrm{CO}$ by a molecular Fe catalyst. Science 338, 90-94 (2012)

89. Weng, Z., Jiang, J., Wu, Y., et al.: Electrochemical $\mathrm{CO}_{2}$ reduction to hydrocarbons on a heterogeneous molecular $\mathrm{Cu}$ catalyst in aqueous solution. J. Am. Chem. Soc. 138, 8076-8079 (2016)

90. Zhong, H., Ly, K.H., Wang, M., et al.: A phthalocyanine-based layered two-dimensional conjugated metal-organic framework as a highly efficient electrocatalyst for the oxygen reduction reaction. Angew. Chem. 131, 10787-10792 (2019)

91. Oh, Y., Hu, X.: Organic molecules as mediators and catalysts for photocatalytic and electrocatalytic $\mathrm{CO}_{2}$ reduction. Chem. Soc. Rev. 42, 2253-2261 (2013)

92. Cheng, N., Ren, L., Xu, X., et al.: Recent development of zeolitic imidazolate frameworks (ZIFs) derived porous carbon based materials as electrocatalysts. Adv. Energy Mater. 8, 1801257 (2018)

93. Dong, L., Gao, Z.A., Lin, N.: Self-assembly of metal-organic coordination structures on surfaces. Prog. Surf. Sci. 91, 101-135 (2016)

94. Elemans, J.A.A.W., Lei, S., Feyter, S.D.: Molecular and supramolecular networks on surfaces: from two-dimensional crystal engineering to reactivity. Angew. Chem. Int. Ed. 48, 7298-7332 (2009)

95. Gottfried, J.M.: Surface chemistry of porphyrins and phthalocyanines. Surf. Sci. Rep. 70, 259-379 (2015)

96. Auwärter, W., Écija, D., Klappenberger, F., et al.: Porphyrins at interfaces. Nat. Chem. 7, 105-120 (2015)

97. Zhang, W., Lai, W., Cao, R.: Energy-related small molecule activation reactions: oxygen reduction and hydrogen and oxygen evolution reactions catalyzed by porphyrin- and corrole-based systems. Chem. Rev. 117, 3717-3797 (2017)

98. Liu, J., Wöll, C.: Surface-supported metal-organic framework thin films: fabrication methods, applications, and challenges. Chem. Soc. Rev. 46, 5730-5770 (2017)
99. Sedona, F., Marino, M.D., Forrer, D., et al.: Tuning the catalytic activity of $\mathrm{Ag}(110)$-supported Fe phthalocyanine in the oxygen reduction reaction. Nat. Mater. 11, 970977 (2012)

100. Grumelli, D., Wurster, B., Stepanow, S., et al.: Bio-inspired nanocatalysts for the oxygen reduction reaction. Nat. Commun. 4, 2904 (2013)

101. Wurster, B., Grumelli, D., Hötger, D., et al.: Driving the oxygen revolution reaction bynonlinear cooperativity in bimetallic coordination catalysts. J. Am. Chem. Soc. 138, 3623-3626 (2016)

102. Itaya, K.: In situ scanning tunnelling microscopy in electrolyte solutions. Prog. Surf. Sci. 58, 121-247 (1988)

103. Abelev, E., Sezin, N., Ein-Eli, Y.: An alternative isolation of tungsten tips for a scanning tunneling microscope. Rev. Sci. Instrum. 76, 106105 (2005)

104. Salerno, M.: Coating of tips for electrochemical scanning tunneling microscopy by means of silicon, magnesium, and tungsten oxides. Rev. Sci. Instrum. 81, 093703 (2010)

105. Kolb, D.M., Schneider, J.: The study of reconstructed electrode surfaces: $\mathrm{Au}(100)-(5 \times 20)$. Surf. Sci. 162, 764-775 (1985)

106. Esplandiu, M.J., Schneeweiss, M.A., Kolb, D.K.: An in situ scanning tunneling microscopy study of Ag electrodeposition on $\mathrm{Au}(111)$. Phys. Chem. Chem. Phys. 1, 4847-4854 (1999)

107. Magnussen, O.M., Hotlos, J., Beitel, G., et al.: Atomic structure of ordered copper adlayers on single-crystalline gold electrodes. J. Vac. Sci. Technol. B 9, 969-975 (1991)

108. Wan, L.-J., Moriyama, T., Ito, M., et al.: In situ STM imaging of surface dissolution and rearrangement of a Pt-Fe alloy electrocatalyst in electrolyte solution. Chem. Commun. 1, 58-59 (2002)

109. Yau, S.L., Moriyama, T., Uchida, H., et al.: In situ STM observation with atomic resolution on platinum film electrodes formed by a sputtering method. Chem. Commun. 22, 2279-2280 (2000)

110. Schlaup, C., Horch, S., et al.: EC-STM study of the initial stages of the electrochemical $\mathrm{Au}(111)-\mathrm{Cd}$ alloy formation. Surf. Sci. 632, 126-134 (2015)

111. Sun, S.G., Cai, W.-B., Wan, L.-J., et al.: Infrared absorption enhancement for $\mathrm{CO}$ adsorbed on Au films in perchloric acid solutions and effects of surface structure studied by cyclic voltammetry, scanning tunneling microscopy, and surface-enhanced IR spectroscopy. J. Phys. Chem. B 103, 2460-2466 (1999)

112. Kim, Y.G., Baricuatro, J.H., Javier, A., et al.: The evolution of the polycrystalline copper surface, first to $\mathrm{Cu}(111)$ and then to $\mathrm{Cu}(100)$, at a fixed $\mathrm{CO} 2 \mathrm{RR}$ potential: a study by operando EC-STM. Langmuir 30, 15053-15056 (2014)

113. Peterson, A.A., Abild-Pedersen, F., Studt, F., et al.: How copper catalyzes the electroreduction of carbon dioxide into hydrocarbon fuels. Energy Environ. Sci. 3, 1311-1315 (2010)

114. Kuhl, K.P., Hatsukade, T., Cave, E.R., et al.: Electrocatalytic conversion of carbon dioxide to methane and methanol on transition metal surfaces. J. Am. Chem. Soc. 136, 14107-14113 (2014)

115. Hahn, C., Hatsukade, T., Kim, Y.G., et al.: Engineering $\mathrm{Cu}$ surfaces for the electrocatalytic conversion of $\mathrm{CO}_{2}$ : controlling selectivity toward oxygenates and hydrocarbons. Proc. Natl. Acad. Sci. USA 114, 5918-5923 (2017)

116. Baricuatro, J.H., Kim, Y.G., Korzeniewski, C.L.: Seriatim ECSTM-ECPMIRS of the adsorption of carbon monoxide on $\mathrm{Cu}(100)$ in alkaline solution at $\mathrm{CO}_{2}$-reduction potentials. Electrochem. Commun. 91, 1-4 (2018)

117. Kim, Y.G., Javier, A., Baricuatro, J.H., et al.: Surface reconstruction of pure- $\mathrm{Cu}$ single-crystal electrodes under $\mathrm{CO}$ reduction potentials in alkaline solutions: a study by seriatim ECSTM-DEMS. J. Electroanal. Chem. 780, 290-295 (2016)

118. Bae, S.E., Stewart, K.L., Gewirth, A.A.: Nitrate adsorption and reduction on $\mathrm{Cu}(100)$ in acidic solution. J. Am. Chem. Soc. 129, 10171-10180 (2007) 
119. Bondos, J.C., Andrew, A.G., Ralph, G.N.: Observation of uniaxial structures of under potentially deposited cadmium on $\mathrm{Au}(111)$ with in situ scanning tunneling microscopy. J. Phys. Chem. 100, 8617-8620 (1996)

120. Damian, A., Maroun, F., Allongue, P.: Electrochemical growth and dissolution of $\mathrm{Ni}$ on bimetallic $\mathrm{Pd} / \mathrm{Au}(111)$ substrates. Electrochim. Acta 55, 8087-8099 (2010)

121. Lay, M.D., Stickney, J.L.: Electrode position of Au-Cd alloy nanostructures on $\mathrm{Au}(111)$. J. Am. Chem. Soc. 125, 1352-1355 (2003)

122. Del Barrio, M.C., García, S.G., Salinas, D.R.: Alloy formation in the system $\mathrm{Au}(111) / \mathrm{Cd}$ during the UPD process. Electrochem. Commun. 6, 762-766 (2004)

123. Del Barrio, M.C., Salinas, D.R., García, S.G.: Electrochemical and in situ STM study of the alloy formation in the system $\mathrm{Au}(100) / \mathrm{Cd}$. Electrochim. Acta 130, 164-169 (2014)

124. Jurca, H.F., Damian, A., Gougaud, C., et al.: Epitaxial electrodeposition of $\mathrm{Fe}$ on $\mathrm{Au}(111)$ : structure, nucleation, and growth mechanisms. J. Phys. Chem. C 120, 16080-16089 (2016)

125. Di, N., Damian, A., Maroun, F., et al.: Influence of potential on the electrodeposition of Co on $\mathrm{Au}(111)$ by in situ STM and reflectivity measurements. J. Electrochem. Soc. 163, D3062D3068 (2016)

126. Madry, B., Wandelt, K., Nowicki, M.: Deposition of copper multilayers on $\mathrm{Au}(111)$ in sulfuric acid solution: an electrochemical scanning tunneling microscopy study. Surf. Sci. 637, 77-84 (2015)

127. Madry, B., Wandelt, K., Nowicki, M.: Sulfate structures on copper deposits on $\mathrm{Au}(111)$ : in situ STM investigations. Electrochim. Acta 217, 249-261 (2016)

128. Varela, A.S., Schlaup, C., Jovanov, Z.P., et al.: $\mathrm{CO}_{2}$ electroreduction on well-defined bimetallic surfaces: $\mathrm{Cu}$ over layers on Pt(111) and Pt(211). J. Phys. Chem. C 117, 20500-20508 (2013)

129. Madry, B., Morawski, I., Kosmala, T., et al.: Porphyrin layers at $\mathrm{Cu} / \mathrm{Au}(111)$-electrolyte interface: in situ EC-STM study. Top. Catal. 61, 1335-1349 (2018)

130. Maroun, F., Ozanam, F., Magnussen, O.M., et al.: The role of atomic ensembles in the reactivity of bimetallic electrocatalysts. Science 293, 1811-1814 (2001)

131. Kudernac, T., Lei, S., Elemans, J.A.A.W., et al.: Two-dimensional supramolecular self-assembly: nanoporous networks on the surfaces. Chem. Soc. Rev. 38, 402-421 (2009)

132. Yoshimoto, S., Suto, K., Tada, A., et al.: Effect of adlayer structure on the host-guest recognition between calcium and crownether-substituted phthalocyanine arrays on Au single-crystal surfaces. J. Am. Chem. Soc. 126, 8020-8027 (2004)

133. Ou Yang, L.Y., Chang, C.Z., Liu, S.H., et al.: Direct visualization of an aniline admolecule and its electropolymerization on $\mathrm{Au}(111)$ with in situ scanning tunneling microscope. J. Am. Chem. Soc. 129, 8076-8077 (2007)

134. Yoshimoto, S., Sawaguchi, T.: Electrostatically controlled nanostructure of cationic porphyrin diacid on sulfate/bisulfate adlayer at electrochemical interface. J. Am. Chem. Soc. 130, 1594415949 (2008)

135. Bae, S.E., Gewirth, A.A.: In situ EC-STM studies of MPS, SPS, and chloride on $\mathrm{Cu}(100)$ : structural studies of accelerators for dual damascene electrode position. Langmuir 22, 10315-10321 (2006)

136. Wang, D., Wan, L.J.: Electrochemical scanning tunneling microscopy: adlayer structure and reaction at solid/liquid interface. J. Phys. Chem. C 111, 16109-16130 (2007)

137. Li, S.S., Northrop, B.H., Yuan, Q.H., et al.: Surface confined metallosupramolecular architectures: formation and scanning tunneling microscopy characterization. Acc. Chem. Res. 42, 249-259 (2009)

138. Palma, C.A., Bjork, J., Bonini, M., et al.: Tailoring bicomponent supramolecular nanoporous networks: phase segregation, polymorphism, and glasses at the solid-liquid interface. J. Am. Chem. Soc. 131, 13062-13071 (2009)

139. Ciesielski, A., Palma, C.A., Bonini, M., et al.: Towards supramolecular engineering of functional nanomaterials: pre-programming multi-component $2 \mathrm{D}$ self-assembly at solid-liquid interfaces. Adv. Mater. 22, 3506-3520 (2010)

140. Mali, K.S., Adisoejoso, J., Ghijsens, E., et al.: Exploring the complexity of supramolecular interactions for patterning at the liquid-solid interface. Acc. Chem. Res. 45, 1309-1320 (2012)

141. Ciesielski, A., Szabelski, P.J., Rzysko, W., et al.: Concentrationdependent supramolecular engineering of hydrogen-bonded nanostructures at surfaces: predicting self-assembly in $2 \mathrm{D}$. J. Am. Chem. Soc. 135, 6942-6950 (2013)

142. Yoshimoto, S., Tada, A., Itaya, K.: In situ scanning tunneling microscopy study of the effect of iron octaethylporphyrin adlayer on the electrocatalytic reduction of $\mathrm{O}_{2}$ on $\mathrm{Au}(111)$. J. Phys. Chem. B 108, 5171-5174 (2004)

143. Hulsken, B., Hameren, R.V., Gerritsen, J.W., et al.: Real-time single-molecule imaging of oxidation catalysis at a liquid-solid interface. Nat. Nanotechnol. 2, 285-289 (2007)

144. Cai, Z.F., Wang, X., Wang, D., et al.: Cobalt-porphyrin-catalyzed oxygen reduction reaction: a scanning tunneling microscopy study. ChemElectroChem 3, 2048-2051 (2016)

145. Sedona, F., Cicero, M.L., Carlotto, S., et al.: Substrate involvement in dioxygen bond dissociation catalysed by iron phthalocyanine supported on $\mathrm{Ag}(100)$. Chem. Commun. 54, 9418-9421 (2018)

146. Chang, M.H., Kim, N.Y., Chang, Y.H., et al.: $\mathrm{O}_{2}, \mathrm{NO}_{2}$ and $\mathrm{NH}_{3}$ coordination to Co-porphyrin studied with scanning tunneling microscopy on Au(111). Nanoscale 11, 8510-8517 (2019)

147. Den Boer, D., Li, M., Habets, T., et al.: Detection of different oxidation states of individual manganese porphyrins during their reaction with oxygen at a solid/liquid interface. Nat. Chem. 5 , 621-627 (2013)

148. Gu, J.Y., Cai, Z.F., Wang, D., et al.: Single-molecule imaging of iron phthalocyanine-catalyzed oxygen reduction reaction by in situ scanning tunneling microscopy. ACS Nano 10, 8746-8750 (2016)

149. Wang, X., Cai, Z.F., Wang, D., et al.: Molecular evidence for the catalytic process of cobalt porphyrin catalyzed oxygen evolution reaction in alkaline solution. J. Am. Chem. Soc. 141, 7665-7669 (2019)

150. Hötger, D., Etzkorn, M., Morchutt, C., et al.: Stability of metalloporphyrin networks under oxygen reduction and evolution conditions in alkaline media. Phys. Chem. Chem. Phys. 21, 2587-2594 (2019)

151. Magnussen, O.M., Polewska, W., Zitzler, L., et al.: In situ videoSTM studies of dynamic processes at electrochemical interfaces. Faraday Discuss. 121, 43-52 (2002)

152. Polewska, W., Behm, R.J., Magnussen, O.M.: In-situ video-STM studies of $\mathrm{Cu}$ electrodeposition on $\mathrm{Cu}(100)$ in $\mathrm{HCl}$ solution. Electrochim. Acta 48, 2915-2921 (2003)

153. Magnussen, O.M.: Atomic-scale insights into electrode surface dynamics by high-speed scanning probe microscopy. Chem. Eur. J. 25, 12865-12883 (2019)

154. Rosta, M.J., Crama, L., Schakel, P., et al.: Scanning probe microscopes go video rate and beyond. Rev. Sci. Instrum. 76, 053710 (2005)

155. Yanson, Y.I., Schenkel, F., Rost, M.J.: Design of a high-speed electrochemical scanning tunneling microscope. Rev. Sci. Instrum. 84, 023702 (2013) 
156. Esch, F., Dri, C., Spessot, A., et al.: The fast module: an add-on unit for driving commercial scanning probe microscope at video rate and beyond. Rev. Sci. Instrum. 82, 053702 (2011)

157. Matsushima, H., Taranovskyy, A., Haak, C., et al.: Reconstruction of $\mathrm{Cu}(100)$ electrode surfaces during hydrogen evolution. J. Am. Chem. Soc. 131, 10362-10363 (2009)

158. Suto, K., Magnussen, O.M.: In situ video-STM studies of sulfate dynamics on $\mathrm{Au}(111)$. J. Electroanal. Chem. 649, 136-141 (2010)

159. Guézo, S., Taranovskyy, A., Matsushima, H., et al.: Surface dynamics of lead adsorbates at the $\mathrm{Cu}(100)$ electrolyte interface. J. Phys. Chem. C 115(39), 19336-19342 (2011)

160. Yang, Y.C., Magnussen, O.M.: Quantitative studies of adsorbate dynamics at noble metal electrodes by in situ video-STM. Phys. Chem. Chem. Phys. 15, 12480-12487 (2013)

161. Wen, R., Rahn, B., Magnussen, O.M.: In situ video-STM study of adlayer structure and surface dynamics at the ionic liquid/Au (111) interface. J. Phys. Chem. C 120, 15765-15771 (2016)

162. Rahn, B., Magnussen, O.M.: Formation and diffusion of subsurface adsorbates at electrodes. J. Am. Chem. Soc. 140, 9066-9069 (2018)

163. Rahn, B., Magnussen, O.M.: Sulfide surface dynamics on $\mathrm{Cu}(100)$ and $\mathrm{Ag}(100)$ electrodes in the presence of $\mathrm{c}(2 \times 2)$ halide adlayers. ChemElectroChem 5, 3073-3082 (2018)

164. Rahn, B., Wen, R., Deuchler, L., et al.: Coadsorbate-induced reversal of solid-liquid dynamics. Angew. Chem. Int. Ed. 57, 6065-6068 (2018)

165. Möller, R., Esslinger, A., Koslowski, B.: Noise in vacuum tunneling: application for a novel scanning microscope. Appl. Phys. Lett. 55, 2360-2362 (1989)

166. Möller, R., Esslinger, A., Koslowski, B.: Thermal noise in vacuum scanning tunneling microscopy at zero bias voltage. J. Vac. Sci. Technol. A8, 590-593 (1990)

167. Schaffert, J., Cottin, M.C., Sonntag, A., et al.: Imaging the dynamics of individually adsorbed molecules. Nat. Mater. 12, 223-227 (2013)

168. Schaffert, J., Cottin, M.C., Sonntag, A., et al.: Scanning noise microscopy. Rev. Sci. Instrum. 84, 043702 (2013)

169. Pfisterer, J.H.K., Liang, Y., Schneider, O., et al.: Direct instrumental identification of catalytically active surface sites. Nature 549, 74-77 (2017)

170. Stöckle, R.M., Suh, Y.D., Deckert, V., et al.: Nanoscale chemical analysis by tip-enhanced Raman spectroscopy. Chem. Phys. Lett. 318, 131-136 (2000)

171. Pettinger, B., Ren, B., Picardi, G., et al.: Nanoscale probing of adsorbed species by tip-enhanced Raman spectroscopy. Phys. Rev. Lett. 92, 096101 (2004)

172. Steidtner, J., Pettinger, B.: Tip-enhanced Raman spectroscopy and microscopy on single dye molecules with $15 \mathrm{~nm}$ resolution. Phys. Rev. Lett. 100, 236101 (2008)

173. Zhang, R., Zhang, Y., Dong, Z.C., et al.: Chemical mapping of a single molecule by plasmon-enhanced Raman scattering. Nature 498, 82-86 (2013)

174. Jiang, S., Zhang, Y., Zhang, R., et al.: Distinguishing adjacent molecules on a surface using plasmon-enhanced Raman scattering. Nat. Nanotechnol. 10, 865-869 (2015)

175. Pozzi, E.A., Goubert, G., Chiang, N., et al.: Ultrahigh-vacuum tip-enhanced Raman spectroscopy. Chem. Rev. 117, 4961-4982 (2018)

176. Nguyen, D., Kang, G., Chiang, N., et al.: Probing molecular-scale catalytic interactions between oxygen and cobalt phthalocyanine using tip-enhanced Raman spectroscopy. J. Am. Chem. Soc. 140, 5948-5954 (2018)

177. Zhong, J.H., Jin, X., Meng, L., et al.: Probing the electronic and catalytic properties of a bimetallic surface with $3 \mathrm{~nm}$ resolution. Nat. Nanotechnol. 12, 132-136 (2017)
178. Hartman, T., Wondergem, C.S., Kumar, N., et al.: Surface- and tip-enhanced Raman spectroscopy in catalysis. J. Phys. Chem. Lett. 7, 1570-1584 (2016)

179. Zeng, Z.C., Huang, S.C., Wu, D.Y., et al.: Electrochemical tipenhanced Raman spectroscopy. J. Am. Chem. Soc. 137, 1192811931 (2015)

180. Kurouski, D., Mattei, M., Van Duyne, R.P.: Probing redox reactions at the nanoscale with electrochemical tip-enhanced Raman spectroscopy. Nano Lett. 15, 7956-7962 (2015)

181. Touzalin, T., Joiret, S., Maisonhaute, E., et al.: Capturing electrochemical transformations by tip-enhanced Raman spectroscopy. Curr. Opin. Electrochem. 6, 46-52 (2017)

182. Touzalin, T., Joiret, S., Lucas, I.T., et al.: Electrochemical tipenhanced Raman spectroscopy imaging with $8 \mathrm{~nm}$ lateral resolution. Electrochem. Commun. 108, 106557 (2019)

183. Hammer, B., Nørskova, J.K.: Electronic factors determining the reactivity of metal surfaces. Surf. Sci. 343, 211-220 (1995)

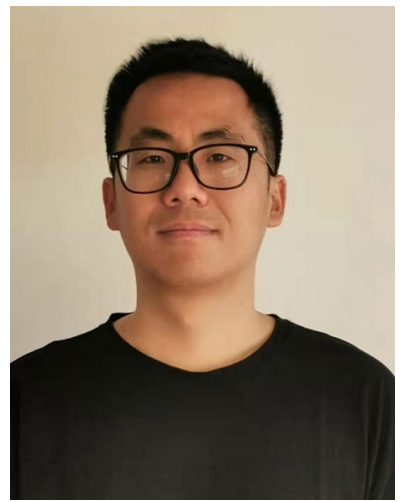

Haifeng Feng received his Ph.D in the Institute for Superconducting and Electronic Materials (ISEM), at University of Wollongong in 2018. He currently works as a postdoc fellow in the STM group in ISEM. His major research interests include surface science, scanning probe microscopy and its applications on 2D materials and surface catalysis.

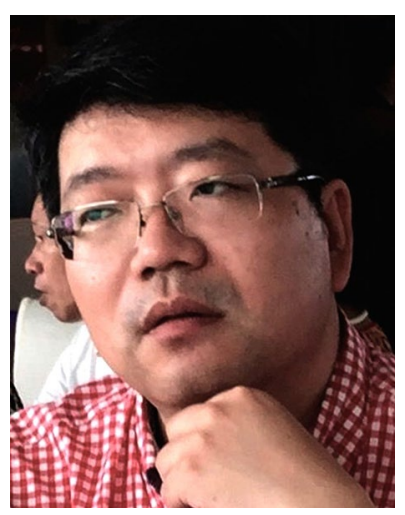

Xun $\mathrm{Xu}$ is currently a senior research fellow in the Institute for Superconducting and Electronic Materials at University of Wollongong. His research interests cover the synthesis and characterization of two-dimensional materials, superconductors and liquid metals.

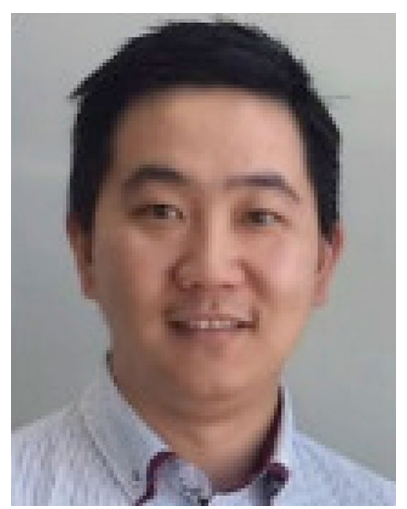

Yi Du received his Ph.D. degree from the Institute for Superconducting and Electronic Materials at University of Wollongong in 2011. His research interests include surface physics and chemistry, two-dimensional materials, and catalysis studied by using scanning tunneling microscopy and angle-resolved photoemission spectroscopy. 


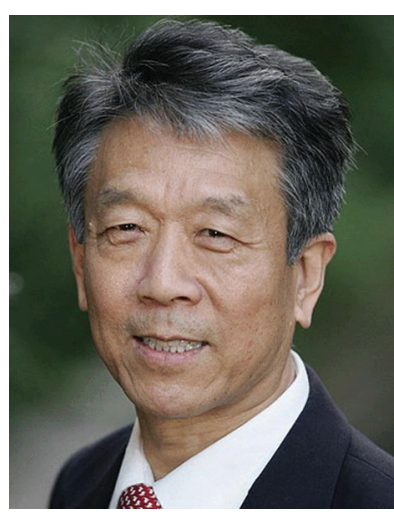

Shi Xue Dou is a Distinguished Professor of Institute for Superconducting and Electronic Materials (ISEM) at Australian Institute of Innovative Materials, University of Wollongong. He was elected as a Fellow of the Australian Academy of Technological Science and Engineering in 1994. He was awarded a Ph.D. by Dalhousie University, Canada, in 1984 and a D.Sc. by the University of New South Wales in 1998 and three Australian Professorial Fellowships by Australian Research Council in 1993,

2002 and 2007. He received the Australian Government's Centenary Medal in 2003, the Engineering Excellence Award highly commended in 2006, finalist of Eureka Award for Science Leadership in 2010 and finalist of Eureka Award for mentoring in 2013, Vice-Chancellors Senior Excellence Award in 2008, Vice-Chancellor Outstanding Partnership Award in 2012, Life Achievement award from ASTS in 2018 and Australian Order of Member (AM) in 2019. He is program leader for the ongoing Automotive CRC 2020 and the ARENA Smart Sodium Storage System program. 